University of Wollongong

Research Online

Faculty of Engineering and Information

Faculty of Engineering and Information

Sciences - Papers: Part A

Sciences

$1-1-2016$

Experimental investigation of the behaviour of concrete beams reinforced with GFRP bars under static and impact loading

Matthew Goldston

University of Wollongong, mwg278@uowmail.edu.au

Alex M. Remennikov

University of Wollongong, alexrem@uow.edu.au

M Neaz Sheikh

University of Wollongong, msheikh@uow.edu.au

Follow this and additional works at: https://ro.uow.edu.au/eispapers

Part of the Engineering Commons, and the Science and Technology Studies Commons

Research Online is the open access institutional repository for the University of Wollongong. For further information contact the UOW Library: research-pubs@uow.edu.au 


\title{
Experimental investigation of the behaviour of concrete beams reinforced with GFRP bars under static and impact loading
}

\begin{abstract}
Composite materials, including Fibre Reinforced Polymer (FRP) bars, have been gaining momentum as alternatives to traditional steel reinforcements in civil and structural engineering sectors. FRP materials are non-corrosive, non-conductive, and lightweight and possess high longitudinal tensile strength, which are advantageous for their use in civil infrastructure. This paper presents the results of an experimental investigation into the effects of the use of glass FRP (GFRP) bars as internal reinforcement on the behaviour of concrete beams. Both static and dynamic (impact) behaviours of the beam have been investigated. Twelve GFRP reinforced concrete (RC) beams were designed, cast and tested. Six GFRP RC beams were tested under static loading to examine the failure modes and associated energy absorption capacities. The remaining six GFRP RC beams were tested under impact loading using a drop hammer machine at the University of Wollongong. GFRP RC beams with higher reinforcement ratio showed higher post cracking bending stiffness and experienced flexural-critical failure under static loading. However, GFRP RC beams under impact loading, regardless of their shear capacity, experienced a "shear plug" type of failure around the impact zone. Energy absorption capacities of beams were determined. The average dynamic amplification factor was calculated as 1.15 , indicating higher dynamic moment capacities compared to static moment capacities (15-20\% increase). Reinforcement ratio and the strength of concrete influenced the behaviour of GFRP RC beams.
\end{abstract}

\section{Keywords}

reinforced, investigation, gfrp, bars, under, static, impact, loading, behaviour, concrete, beams, experimental

\section{Disciplines \\ Engineering | Science and Technology Studies}

\section{Publication Details}

Goldston, M., Remennikov, A. \& Sheikh, M. Neaz. (2016). Experimental investigation of the behaviour of concrete beams reinforced with GFRP bars under static and impact loading. Engineering Structures, 113 220-232. 


\title{
EXPERIMENTAL INVESTIGATION OF THE BEHAVIOUR OF CONCRETE BEAMS REINFORCED WITH GFRP BARS UNDER STATIC AND IMPACT LOADING
}

\author{
M.Goldston ${ }^{1}$, A. Remennikov ${ }^{2, *}$ and M. Neaz Sheikh ${ }^{3}$
}

Affiliation:

${ }^{1}$ Postgraduate Research Student, School of Civil, Mining and Environmental Engineering, University of Wollongong, Australia

${ }^{2}$ Associate Professor, School of Civil, Mining and Environmental Engineering, University of Wollongong, Australia

${ }^{3}$ Senior Lecturer, School of Civil, Mining and Environmental Engineering, University of Wollongong, Australia

\section{Correspondence:}

Name: A. Remennikov

Address: School of Civil, Mining and Environmental Engineering

University of Wollongong

Northfields Avenue, Wollongong NSW 2522

E-mail: alexrem@uow.edu.au

Telephone: 61242215574

* Corresponding authors 


\section{Research Highlights}

- Flexural behaviour of GFRP RC beams has been investigated.

- Effects of concrete strength and reinforcement ratio on the behaviour of GFRP RC beams have been investigated.

- Failure modes of GFRP RC beams under static and impact loading are identified.

- Dynamic moment capacities of GFRP RC beams showed 15-20\% increase compared to static moment capacities of the beams, which is important for designing GFRP RC beams under dynamic loading. 


\title{
EXPERIMENTAL INVESTIGATION OF THE BEHAVIOUR OF CONCRETE BEAMS REINFORCED WITH GFRP BARS UNDER STATIC AND IMPACT LOADING
}

\author{
M.Goldston ${ }^{1}$, A. Remennikov ${ }^{2}$ and M. Neaz Sheikh ${ }^{3}$ \\ ${ }^{1}$ Postgraduate Student, School of Civil, Mining and Environmental Engineering, University \\ of Wollongong, Australia \\ ${ }^{2}$ Associate Professor, School of Civil, Mining and Environmental Engineering, University of \\ Wollongong, Australia \\ ${ }^{3}$ Senior Lecturer, School of Civil, Mining and Environmental Engineering, University of \\ Wollongong, Australia
}

\begin{abstract}
Composite materials, including Fibre Reinforced Polymer (FRP) bars, have been gaining momentum as alternatives to traditional steel reinforcements in civil and structural engineering sectors. FRP materials are non-corrosive, non-conductive, and lightweight and possess high longitudinal tensile strength, which are advantageous for their use in civil infrastructure. This paper presents the results of an experimental investigation into the effects of the use of glass FRP (GFRP) bars as internal reinforcement on the behaviour of concrete beams. Both static and dynamic (impact) behaviours of the beam have been investigated. Twelve GFRP reinforced concrete (RC) beams were designed, cast and tested. Six GFRP RC beams were tested under static loading to examine the failure modes and associated energy absorption capacities. The remaining six GFRP RC beams were tested under impact loading using a drop hammer machine at the University of Wollongong. GFRP RC beams with higher reinforcement ratio showed higher post cracking bending stiffness and experienced flexuralcritical failure under static loading. However, GFRP RC beams under impact loading, regardless of their shear capacity, experienced a "shear plug" type of failure around the impact zone. Energy absorption capacities of beams were determined. The average dynamic amplification factor was calculated as 1.15 , indicating higher dynamic moment capacities compared to static moment capacities (15-20\% increase). Reinforcement ratio and the strength of concrete influenced the behaviour of GFRP RC beams.
\end{abstract}

Keywords: GFRP, Reinforced Concrete, Beams, Flexure, Shear, Concrete Strength, Reinforcement Ratio, Energy Absorption 


\section{INTRODUCTION}

Fibre reinforced polymer (FRP) bar is an innovative solution and viable substitute to conventional steel reinforcement for civil engineering structures. FRP is a composite material manufactured of a polymer matrix reinforced with fibres, usually glass (Glass Fibre Reinforced Polymer, GFRP), carbon (Carbon Fibre Reinforced Polymer, CFRP) or aramid (Aramid Fibre Reinforced Polymer, AFRP). The polymer matrix is typically an epoxy resin which provides bond to the fibres. The advantages of FRP bars include low weight to strength ratio (1/5 to $1 / 4$ times of the density of steel), high longitudinal tensile strength, and nonmagnetic characteristics. Although the initial cost of FRP reinforcement is higher than steel reinforcement, the total life cycle cost of the structure or structural components reinforced with FRP is lower, as significantly less maintenance costs are required for structures or structural components reinforced with FRP.

FRP has been used extensively for strengthening structural components including the application of FRP sheets or plates as external reinforcement to the exterior surface of beams [1] and slabs [2]. Also, FRP sheets have been used to repair damaged reinforced concrete (RC) columns [3]. The use of FRP as external reinforcement not only provides additional strength but also provides confinement to a deteriorated structure. FRP bars have also been used as internal reinforcement in reinforced concrete beams [4] and slabs [5]. The use of FRP bars in civil infrastructures is advantageous especially for structures located in marine and salt environments. As FRP is a non-corrosive material, they are resistant to corrosion due to the exposure to de-icing salts. It is noted that, for conventional steel RC structures, exposure to harsh environments including moisture and temperature reduces the alkalinity of the concrete and causes corrosion of the steel reinforcement and ultimately results in the loss of serviceability and strength. Internal FRP reinforcement is also beneficial in increasing the load carrying capacity of beams, especially for beams constructed with high strength concrete [6]. Also, increasing the FRP tensile reinforcement ratio is a key factor in enhancing load carrying capacity and controlling deflection [7].

GFRP RC beams experience higher deflections and larger crack widths compared to steel RC beams with equivalent reinforcement ratios [8]. This is because of the low elastic modulus (35-51 GPa) of the GFRP reinforcement, as documented in the guidelines for the design and construction of structural concrete reinforced with FRP bars in American Concrete Institute Committee (ACI) [9]. In addition, FRP bars show linear-elastic behaviour up to failure 
without exhibiting any yielding, unlike the behaviour of steel reinforcing bars [10]. Thus, FRP RC beams subjected to loading experience a bi-linear load-deflection relationship up to failure, where the ductile type failure exhibited by steel RC members does not occur [6]. Also, due to the lower stiffness of the FRP material, FRP RC beams display lower postcracking bending stiffness than traditional steel reinforced RC beams [11]. Therefore, to prevent FRP rupture, which can be catastrophic and may occur without warning, it is recommended to design the beams to fail by concrete crushing (over-reinforced). This type of failure is also classified as brittle but is more desirable for FRP RC flexural members [9]. To compensate for the lack of ductility, the margin of safety for the design of FRP RC flexural member is higher than the margin of safety for steel RC flexural members [9]. For FRP rupture to govern the design, a strength reduction factor of 0.55 is recommended [9]. For over-reinforced FRP RC beams, the strength reduction factor is dependent on the reinforcement ratio and balanced reinforcement ratio [9]. It is noted that beams reinforced with FRP bars carry higher load than the beams reinforced with steel bars. Hence, to control the deflection rate, higher reinforcement ratio in the tension zone is required for FRP RC beams [7].

Significant amount of research was carried out on the behaviour of FRP RC beams under static loading [12-19]. Previous research mostly investigated the behaviour of doubly reinforced FRP RC beams with CFRP or GFRP bars. The compressive strength of concrete was kept relatively constant. The compressive strength of concrete was predominately between 30 to $47 \mathrm{MPa}$. Kobraei et al [14] investigated the behaviour of GFRP shear links in $\mathrm{RC}$ beams constructed with concrete of compressive strength $95 \mathrm{MPa}$. Differences in the behaviour of FRP RC beam for the compressive strength of concrete are evident. However, only a limited number of studies systematically investigated the influence of the compressive strength of concrete on the performance of GFRP RC beams [20].

The dynamic performance of steel reinforced RC beams was studied in Ref. [21-23]. Under impact loading, research studies reported that regardless of the shear capacity of the RC beams, beams showed severe diagonal shear cracks within the impact zone. Beams designed for higher shear capacity showed the ability to absorb more energy [22]. Ohnuma et al [23] observed that the velocity of the drop hammer was a significant factor for the shear failure of the beams (shear failure). At lower speeds, beams showed a flexural-critical type of failure, whereas critical shear cracking was observed at higher speeds. Although the behaviour of steel reinforced RC beams under impact loading has been extensively studied, there have not 
been any studies so far addressing the performance of GFRP RC beams under impact loading.

In this study, twelve GFRP RC beams were cast and tested under static and impact loadings. The influences of concrete strength and reinforcement ratio have been examined. Six beams were cast with 28 day concrete compressive strength of $40 \mathrm{MPa}$, whilst the remaining six were cast with 28 day concrete compressive strength of $80 \mathrm{MPa}$. GFRP bars were used as the flexural reinforcement. The beams were doubly reinforced. It is noted that ACI [9] does not recommended using FRP bars in compression for low compressive strength to tensile strength ratio. However, in many instances, compression reinforcement cannot be avoided, e.g., to provide stability of the stirrups to form reinforcement cage [9]. This study focuses on the behaviour of GFRP RC beams in terms of load-deflection relationship, crack pattern, energy absorption capacity and the differences in failure modes under static and impact loading.

\section{EXPERIMENTAL PROGRAM}

\subsection{Preliminary Tests for Material Properties}

Concrete cylinders with $100 \mathrm{~mm}$ in diameter and $200 \mathrm{~mm}$ in height were tested for compressive strength of concrete. The compressive strength of the concrete was measured on 28 days and on the day of static and impact testings. The average compressive strength of three cylinders has been reported herein. Concretes of two different compressive strengths were used in the experimental program. The average concrete compressive strengths were 40 $\mathrm{MPa}$ and $80 \mathrm{MPa}$, on the $28^{\text {th }}$ day.

Three steel reinforcing bars specimens were tested for the tensile properties of shear links according to American Society for Testing and Materials (ASTM) 24]. The average values of three test specimens have been reported herein. The average ultimate tensile strength and yield strength were calculated as $645 \mathrm{MPa}$ and $615 \mathrm{MPa}$, respectively.

Nine GFRP bar specimens were tested to measure the tensile strength $\left(f_{u}\right)$, modulus of elasticity $\left(E_{f}\right)$ and rupture strain $\left(\varepsilon_{f u}\right)$. Tensile testing of GFRP bars is very different from that of conventional steel reinforcing bars. Due to the low compressive strength of GFRP reinforcement compared to the tensile strength, steel anchors were attached to each end of the test specimen using an expansive cement grout, Bristar 100, as recommended by ASTM [25]. This provided a uniform pressure on the GFRP reinforcing bar as well as prevented slip as the 
tensile loading increased. The GFRP bars were aligned in the steel anchors using a circular steel ring at each end. The internal diameter of the circular ring was same as the diameter of the GFRP bar specimens. The GFRP bars were held in place using support stands and clamps.

The GFRP bars were positioned into the jaws of the Instron Tensile machine and clamped using a pressurised hydraulic system as shown in Fig. 1. All specimens were loaded at a rate of $1 \mathrm{~mm} / \mathrm{min}$. An extensometer was attached at the mid-height of the specimens to measure the strain within the free length $(L)$, defined as length between steel anchors.

All GFRP tensile test specimens were loaded until failure. Fig. 2 displays the mode of failure of GFRP bars. The failure occurred within the free length of the bars and was due to rupture and splitting of the fibres. Stress-strain behaviour of the GFRP bars was linear up to the point of failure as shown in Fig. 3. Unlike steel bars, the GFRP bars do not show clear yielding condition. Table 1 provides details of the test specimens including the steel anchor length $\left(L_{a}\right)$, total length of tensile test specimen $\left(L_{t o t}\right)$ and a summary of the tensile test results for all nine GFRP bars. It is noted that the mechanical properties of different size FRP bars may vary due to the variations in the volume fractions of fibres, type of resin, orientation of fibres and quality control (ACI [9]).

\subsection{Details of GFRP RC Beams}

A total of 12 GFRP rectangular RC beams were constructed with a cross-sectional dimension of 100 x $150 \mathrm{~mm}$ and an overall length of $2400 \mathrm{~mm}$ as shown in Fig. 4(a). The experimental program was divided into two series. The first series of six beams was used to investigate the flexural behaviour of GFRP RC beams under static loading (S) (four-point bending). The main parameters investigated were the load-deflection behaviour, energy absorption capacity, crack pattern and failure mode. The second series of six beams was used to investigate the behaviour of beams under impact loading (I). The main aim was to investigate the effect of impact force, dynamic mid-span deflections, dynamic GFRP tensile strain and dynamic reaction forces including inertial forces and support reaction forces. The test variables were the longitudinal reinforcement ratio $\left(\rho_{f}\right)$ and concrete compressive strength. Three different diameter rebars were used: $6.35 \mathrm{~mm}(\# 2), 9.53 \mathrm{~mm}(\# 3)$ and $12.7 \mathrm{~mm}(\# 4)$, providing reinforcement ratios of $0.5 \%, 1.0 \%$ and $2.0 \%$, respectively. The GFRP RC beams were designed to be doubly reinforced, with two GFRP bars placed in compression and two in 
tension zones. $4 \mathrm{~mm}$ diameter steel stirrups at $100 \mathrm{~mm}$ centres were used as shear reinforcement as shown in Fig. 4(b). All GFRP RC beams had a clear cover of $15 \mathrm{~mm}$ on all four sides.

GFRP RC beams are labelled (Column 1 of Table 2) in the form A-B-C-D. The A (first and second letter) represents the concrete compressive strength, B (third and fourth letter) represents the GFRP reinforcement bar type, C (fifth and sixth letter) represents the reinforcement ratio and $\mathrm{D}$ (seventh letter) represents the type of loading applied to the GFRP RC beams (S represents static loading and I represents impact loading). For example, 40-\#20.5-S in Column 1 of Table 2 represents the test beam constructed with concrete strength of $40 \mathrm{MPa}$, GFRP reinforcement diameter of $6.35 \mathrm{~mm}(\# 2)$, reinforcement ratio of $0.5 \%$ and tested under static loading (S). Table 2 provides details of GFRP RC beams, including the tensile reinforcement area $\left(A_{f}\right)$, effective depth $(d)$, design nominal moment capacity $\left(M_{n}\right)$ and design failure modes.

The GFRP RC beams were designed according to ACI [9] to investigate failure modes including rupture of the GFRP bars (under-reinforced) and concrete crushing (overreinforced), assuming the maximum usable compressive strain in the concrete $\left(\varepsilon_{c u}\right)$ is 0.003 . Design nominal moment capacity of the beam $\left(M_{n}\right)$ was calculated using rectangular stress block for over-reinforced sections, similar to that for structures reinforced with steel bars. ACI [9] provides a conservative and simple approach for $M_{n}$ for under-reinforced sections (since $\varepsilon_{c u}$ is not attained). Design nominal moment capacity $\left(M_{n}\right)$ and the ratio $\rho_{f} / \rho_{f b}$ was calculated using the experimental data from the material testing results. For failure of the FRP RC beam by crushing of the concrete, the FRP reinforcement ratio $\left(\rho_{f}\right)$ must exceed the balanced reinforcement ratio $\left(\rho_{f b}\right)$. For GFRP rupture to govern the design, $\rho_{f b}$ must exceed $\rho_{f}$. Eight beams were designed as over-reinforced, two as under-reinforced and the remaining two beams were designed to have balanced reinforcement $\left(\rho_{f} / \rho_{f b}=1\right.$; rupture of GFRP tensile reinforcement occurs simultaneously with concrete crushing, $\varepsilon_{c u}=0.003$ ). The ratio $\rho_{f} / \rho_{f b}$ was not exactly one for the balanced failure GFRP RC beams but was close to a value of one. The design nominal bending capacity of GFRP RC beam 40-\#3-1.0-S (Table 2) was calculated as 9.93 kN.m. However, for a similar steel RC beam with a reinforcement ratio of $1.0 \%$, the design nominal bending moment capacity was calculated as $8.25 \mathrm{kN} . \mathrm{m}$, assuming yield strength of steel as $500 \mathrm{MPa}$ and modulus of elasticity as 200 GPa. 


\subsection{Instrumentation}

GFRP reinforcement cages were initially constructed by attaching the GFRP longitudinal reinforcement to the steel stirrups at $100 \mathrm{~mm}$ centres. To measure the strain of the tensile reinforcement, the exterior sand coat of the bar was removed. This allowed the strain gauge to attach to the core of the GFRP reinforcement bar. Strain gauges were attached at the centre of each tensile rebar to measure the average strain in the reinforcement of GFRP RC beams tested under static loading. Only one strain gauge was attached to one of the GFRP tensile reinforcement for the beams tested under impact loading. After curing, two strain gauges were attached to the top surface in the mid-span of the GFRP RC beams tested under static loading to measure the concrete strain during loading. The test data were recorded in the high speed data acquisition system, NI-PXI-1050 for impact loading and NI PXIe-1078 for static loading. It is noted that concrete strain was not measured for GFRP RC beams tested under impact loading due to the susceptibility of the damage of strain gauges by the drop hammer.

\section{EXPERIMENTAL SET-UP}

\subsection{Static Testing}

The experimental test set-up of GFRP RC beams under static loading involved placing the beams between two steel I-beams with a clear span of $2 \mathrm{~m}$. There was a $200 \mathrm{~mm}$ overhang at each side. The beams were set up to have simply supported conditions, with a pin support at one end and a roller support at the other end. The simply supported condition allowed the GFRP RC beams to deflect under loading as shown in Fig. 5 and Fig. 6. The GFRP RC beams were displacement controlled, loaded at a rate of $1 \mathrm{~mm} / \mathrm{min}$. The loads were applied at $667 \mathrm{~mm}$ from each support, using a steel spherical ball placed at the centre of the steel Ibeam. The $1000 \mathrm{kN}$ hydraulic controlled load cell used during testing had a smaller load cell attached to the underside. The smaller load cell captured smaller load increments applied to the GFRP RC beams. Mid-span deflection was measured by a linear potentiometer attached to the under-side of each GFRP RC beam. The test data were recorded using the high speed data acquisition system, NI PXIe-1078.

During testing, cracks were marked and the corresponding loads were recorded to examine the behaviour of the beams at different load intervals. The sequence and pattern of the cracks up until failure were also investigated. 


\subsection{Impact Testing}

Six GFRP RC beams were subjected to impact loading applied by the drop hammer apparatus. Similar to the static test set-up, two concrete blocks were fixed to the ground, to allow the beams to be simply supported and subjected to three point dynamic loading as shown in Fig. 7. To measure the beam resistance, load cells were initially calibrated and positioned underneath the concave rollers at both supports of the GFRP RC beams._Rubber straps were used around each support to prevent rebounding of the GFRP RC beams during impact. The drop hammer was attached to a low friction linear bearing and was not absolutely free falling. However, the losses due to friction were not significant which was confirmed using high-speed camera calibrations of velocities of the falling anvil. The drop hammer was lifted into position using a motorised cable. The system included a clutch to brake or stop the mass for interrupted power supply. The mass was connected to a rope which when pulled released the hammer from the cable. A high speed camera was used to capture the progression of damage in the impact zone and for recording dynamic deformations of the GFRP RC beams. The recording rate of the camera was 1000 frames per second. Dynamic mid-span deflections were determined by image processing technique using high-speed camera video recordings. The impact force was measured using the load cell, positioned between the anvil and the tested GFRP RC beams. The mass of the drop hammer was $110 \mathrm{~kg}$ and the height of the drop was $1200 \mathrm{~mm}$ for all GFRP RC beams. The high-speed data acquisition system NI-PXI-1050 was used to record the data, with a frequency of 50,000 samples per second.

\section{EXPERIMENTAL RESULTS AND DISCUSSION}

\subsection{GFRP RC beams under static loading}

The response of all GFRP RC beams under four point bending displayed pre-and postcracking behaviour. Initially, all six GFRP beams displayed high bending stiffness. However, post-cracking, the bending stiffness was significantly lower as a result of the low elastic modulus of the GFRP reinforcement bars $(37.5 \mathrm{GPa}, 55.6 \mathrm{GPa}$ and $48.6 \mathrm{GPa}$ for GFRP reinforcement bars \#2, \#3 and \#4, respectively). After cracking, rate of increase of deflection with load significantly reduced, causing the bending stiffness of the beams to decrease 
significantly, especially for GFRP RC beams with $\rho_{f}=0.5 \%$. For the GFRP RC beam 40\#2-0.5-S, the decrease in bending stiffness from pre- to post- cracking was $92 \%$ and for the GFRP RC beam 80-\#2-0.5-S, the decrease is $96 \%$. However, for higher strength concrete (GFRP RC beam 80-\#2-0.5-S), the bending stiffness in post-cracking was 7\% larger than that of GFRP RC beam 40-\#2-0.5-S. The GFRP RC beams with higher reinforcement ratio $\left(\rho_{f}=1.0 \%\right.$ and $2.0 \%$ ) displayed higher bending stiffness at post-cracking due to the higher elastic modulus of the \#3 and \#4 GFRP reinforcement bars. For the GFRP RC beams with $\rho_{f}=1.0 \%$ and $2.0 \%$, post-cracking stiffness increased by $25 \%$ and $23 \%$, respectively, when the concrete strength increased from $40 \mathrm{MPa}$ to $80 \mathrm{MPa}$.

For the GFRP RC beam with $\rho_{f}=0.5 \%$ (GFRP RC beam 80-\#2-0.5-S), the beam failed in a very brittle manner once the load carrying capacity was reached. There was no prior warning of collapse and the failure occurred due to rupture of GFRP reinforcing bars. Concrete crushing and GFRP tensile ruptured occurred simultaneously at the point of failure for the GFRP RC beam with balanced reinforcement (GFRP RC beam 40-\#2S-0.5-S) as shown in Fig. 8. Whereas, for the four over-reinforced GFRP RC beams, their assumed failure $\left(\varepsilon_{c u}=0.003\right)$ occurred at the first drop in the load carrying capacity. At the time of failure, all GFRP RC beams showed a flexure-critical response, with vertical cracks initially propagating in the pure bending region, before moving closer towards the supports. These cracks continued to expand along the height of the GFRP RC beams towards the compression zone as shown in Fig. 9 for GFRP RC beam 40-\#3-1.0-S. However, the average of the two concrete strain gauges $\left(\varepsilon_{c . a v g}\right)$ did not exactly match the assumed value of 0.003 at the first drop in load carrying capacity as shown in Table 3 . The $\varepsilon_{\text {c.avg }}$ values were $0.0014,0.001$ and 0.0022 for GFRP RC beams 40-\#2-0.5-S, 80-\#2-0.5-S and 80-\#3-1.0-S, respectively, even though concrete crushing occurred on all top surfaces. The average GFRP strain in the tensile reinforcement $\left(\varepsilon_{f r p . a v g}\right)$ for these three GFRP RC beams were not analysed because of the difficulty in capturing accurate strain in the GFRP reinforcement. The difficulties in capturing accurate strain in GFRP reinforcement were due to cracking of concrete along the strain gauges during testing and are not related to the bond-slip behaviour between GFRP reinforcement bars and concrete. For the remaining three GFRP RC beams, results matched with assumptions $\left(\varepsilon_{c u}=0.003\right)$. For GFRP RC beam 40-\#3-1.0-S, at the first drop in load carrying capacity, the average concrete strain on the top surface was 0.0033 . The tensile 
strain in the GFRP reinforcement was less than the rupture strain $(0.98 \%<3.18 \%)$ indicating that the failure was due to concrete crushing.

Concrete strength and reinforcement ratio were thoroughly examined to investigate the influence of these parameters on the GFRP RC beams under static loading. For the two GFRP RC beams with $\rho_{f}=0.5 \%$, regardless of the concrete strength (40 $\mathrm{MPa}$ and $80 \mathrm{MPa}$ ), midspan deflection was similar, $52.5 \mathrm{~mm}$ and $54.5 \mathrm{~mm}$ for GFRP RC beams 40-\#2-0.5-S and 80\#2-0.5-S respectively. But, for when $\rho_{f}>0.5 \%$, especially $\rho_{f}=2.0 \%$, concrete strength influenced more on decreasing the deflection at failure. For $\rho_{f}=1.0 \%$, mid-span deflection was decreased by $7 \%$ for the increase in the strength of concrete from $40 \mathrm{MPa}$ to $80 \mathrm{MPa}$. But for the two GFRP RC beams with $\rho_{f}=2.0 \%$, the beam 40-\#4-2.0-S showed a maximum deflection of $59.9 \mathrm{~mm}$ and beam 80-\#4-2.0-S showed a maximum deflection of $47.3 \mathrm{~mm}$, a reduction in $21 \%$ was observed. The change in the concrete strength moderately improved the load carrying capacity of beams with $\rho_{f}=0.5 \%$ and $\rho_{f}=1.0 \%$; the increase in the load carrying capacity was $12 \%$ and $9 \%$, respectively. However, the load carrying capacity decreased by $0.4 \%$ for GFRP RC beams with $\rho_{f}=2.0 \%$. Fig. 10 and Fig. 11 detail the effect of experimental moment capacity and experimental midspan deflection respectively, with both graphs outlining the influence of the reinforcement ratio and concrete strength.

In terms of change in reinforcement ratio, for the same concrete strength, experimental maximum mid-span deflection (Fig. 11) and moment capacity (Fig. 10) are improved at higher reinforcement ratios and higher concrete strength For the GFRP beams with concrete compressive strength of $40 \mathrm{MPa}$, the load carrying capacity and bending stiffness post cracking were improved by $184 \%$ and $180 \%$, respectively, but the maximum deflection increased $16 \%$ when the reinforcement ratio increased from $\rho_{f}=0.5 \%$ to $\rho_{f}=1.0 \%$. Significant changes in load carrying capacity and bending stiffness post cracking for the change in reinforcement ratio from $\rho_{f}=0.5 \%$ to $\rho_{f}=1.0 \%$ were due to the change in the failure mode from GFRP rupture to concrete crushing. But by increasing the reinforcement ratio from $\rho_{f}=1.0 \%$ to $\rho_{f}=2.0 \%$, the change in the three main parameters (load carrying capacity, deflection and bending stiffness post cracking) were not as significant for concrete strength of $40 \mathrm{MPa}$. Deflection decreased by $0.8 \%$ and load carrying capacity and bending stiffness post cracking increased by only $27 \%$ and $38 \%$, respectively. For concrete strength of $80 \mathrm{MPa}$, load carrying capacity increased by $175 \%$ and $16 \%$ for $\rho_{f}=0.5 \%$ to $1.0 \%$ and $\rho_{f}=1.0 \%$ to $2.0 \%$, respectively. In terms of mid-span deflection, only a $3 \%$ increase 
was noticed for $\rho_{f}=0.5 \%$ to $1.0 \%$ compared to a decrease of $16 \%$ for $\rho_{f}=1.0 \%$ to $2.0 \%$. Fig. 12 details the effect of bending stiffness post cracking based on reinforcement ratio and concrete strength.

The comparison between experimental moment capacity $\left(M_{u}\right)$ and design nominal moment capacity $\left(M_{n}\right)$ according to ACI design guidelines [9] is displayed in Table 4. For the six GFRP RC beams, the ratio of the design nominal moment capacity to the experimental moment capacity outlines the inaccuracies of the design guidelines [9] for under-reinforced or balanced failure specimens, for this experimental study. For the balanced GFRP RC beam (40-\#2-0.5-S), $M_{n} / M_{u}=1.24$, and for the under-reinforced GFRP RC beam (80-\#2-0.5-S), $M_{n} / M_{u}=1.10$, which is un-conservative from a design point of view. For safety purposes, $M_{n} / M_{u}<1$ and thus according to ACI guidelines [9], a conservative strength reduction factor of $\emptyset=0.55$ should be applied for $\rho_{f}<\rho_{f b}$. Technically the balanced GFRP RC beam is under-reinforced $\left(\rho_{f} / \rho_{f b}=0.9\right)$. For the four over-reinforced GFRP RC beams, results for $M_{n} / M_{u}$ were much more conservative. The ratio $M_{n} / M_{u}$ was less than one for all four GFRP RC beams. For design purposes, the strength reduction factor for flexure for over-reinforced sections should be calculated according to $\emptyset=0.3+0.25 \rho_{f} / \rho_{f b}$ for $\rho_{f b}<\rho_{f}<1.4 \rho_{f b}$ or $\emptyset=0.65$ for $\rho_{f} \geq 1.4 \rho_{f b}$.

The energy absorption capacities $\left(E_{1}\right.$ and $\left.E_{2}\right)$ of the GFRP RC beams were calculated as the area enclosed by the load-deflection curve. The energy absorption $E_{1}$ is defined as the energy at the first point of concrete crushing $\left(\varepsilon_{c u}=0.003\right)$ for the four over-reinforced GFRP RC beams or failure for the balanced GFRP RC beam (40-\#2-0.5-S) and under-reinforced GFRP RC beam (80-\#2-0.5-S). An example of calculation of the energy absorption capacity $\left(E_{1}\right.$ and $\left.E_{2}\right)$ is shown in Fig. 13. However the four GFRP RC beams were able to continue to resist load and show signs of reserve capacity (“ductility”), defined as $E_{2}$, up to total collapse, see Fig. 14. GFRP RC Beams 40-\#2-0.5-S and 80-\#2-0.5-S had no reserve capacity as they collapsed due to rupture of the GFRP reinforcement bars. Fig. 15 displays the energy absorption capacity $\left(E_{1}+E_{2}\right)$ of all six GFRP RC beams.

The energy absorption from static testing is a fundamental part in relation to the behaviour of the GFRP RC beams under impact loading. The energy absorption capacity can be equated to the potential energy of the drop hammer $(m g h)$, where $m$ is the mass of the drop hammer, $g$ is acceleration due to gravity and $h$ is the height of the drop hammer to determine the height 
of the drop to cause similar results to static testing in terms of deflection. However to ensure the variables including reinforcement ratio and concrete strength could be analysed, the height of the drop hammer was kept constant at $1200 \mathrm{~mm}$. A height of $1200 \mathrm{~mm}$ was determined based on the energy absorption capacity $\left(E_{1}\right)$ of three of the over-reinforced GFRP RC beams. The average energy absorption capacity of GFRP RC beams 40-\#3-1.0-S, 80-\#3-1.0-S and 80-\#4-2.0-S was $1338 \mathrm{~J}$ and thus using this value a drop hammer height of approximately $1200 \mathrm{~mm}$ was obtained. The velocity $(v=\sqrt{2 g h})$ of the drop hammer was thus calculated as $4.8 \mathrm{~m} / \mathrm{s}$ for a $1200 \mathrm{~mm}$ drop hammer height.

Reinforcement ratio affects the energy absorption capacity $\left(E_{1}\right)$ more significantly compared to concrete compressive strength. For beams with nominal concrete strength of $40 \mathrm{MPa}$, energy absorption increased by $216 \%$ (from $435 \mathrm{~J}$ to $1373 \mathrm{~J}$ ) for the increase in the reinforcement ratio from $0.5 \%$ to $1.0 \%$ and $30 \%$ for the increase in the reinforcement ratio from $1.0 \%$ to $2.0 \%$ (from $1373 \mathrm{~J}$ to $1790 \mathrm{~J}$ ). For beams with a nominal concrete strength of $80 \mathrm{MPa}$, energy absorption increased $161 \%$ for an increase in the reinforcement ratio from $0.5 \%$ to $1.0 \%$ (from $518 \mathrm{~J}$ to $1350 \mathrm{~J}$ ), but a decrease of $4 \%$ was noticed for an increase in the reinforcement ratio from $1.0 \%$ to $2.0 \%$ (from $1350 \mathrm{~J}$ to $1292 \mathrm{~J}$ ). The reason for this decrease is that the GFRP RC beams with the highest reinforcement ratio display lower deflections and higher load carrying capacities and thus the area under the load-deflection is smaller compared to that of a GFRP RC beam with a higher deflection and lower reinforcement ratio. However, for the change of the nominal concrete strength from $40 \mathrm{MPa}$ to $80 \mathrm{MPa}, 19 \%$ increase in the energy absorption was observed for the GFRP RC beams with $\rho_{f}=0.5 \%$ and a $2 \%$ and $28 \%$ decrease for $\rho_{f}=1.0 \%$ and $\rho_{f}=2.0 \%$, respectively. The experimental results for all GFRP RC beams under static loading are summarised in Table 3.

\subsection{GFRP RC beams under impact loading}

When a beam is subjected to a falling mass, the impact force, $I(t)$, is resisted by two transient dynamic mechanisms: inertial resistance and beam flexural resistance. As the drop hammer strikes the beam, the beam accelerates in the direction of the impact force, resulting in inertial forces directed in the opposite direction. The inertial force can be defined as the mass of the beam multiplied by the acceleration, $a(x, t)$ along the length of the beam $(L)$ or as, $\int_{0}^{L} \bar{m} a(x, t) d x$, where $\bar{m}$ is the mass of the beam per unit length. Inertial forces of the 
overhangs were ignored as they were only $15 \%$ of the total mass of the GFRP RC beams. The dynamic vertical force equilibrium of a GFRP RC beam under impact loading dynamic along the beam can be expressed as:

$$
\int_{0}^{L} \bar{m} a(x, t) d x+\mathrm{R}_{1}(t)+\mathrm{R}_{2}(t)-I(t)=0
$$

As previously discussed, for the GFRP RC under static loading, test results revealed a flexural response, with all beams experiencing vertical flexural cracks before compression failure of the concrete (i.e., $\varepsilon_{c u}=0.003$ ) for the over-reinforced GFRP RC beams. For the GFRP RC beams 80-\#3-1.0-I and 80-\#4-2.0-I as shown in Fig. 16 and Fig. 17 respectively, crack patterns showed minor shear cracking around the impact area, with very minimal concrete crushing occurring on the top surface. The GFRP RC beams under impact loading displayed a "shear plug" type of failure. The shear cracks on either side of the impact point were roughly parallel, at angles of approximately 45 degrees. Few very small and minor flexural cracks were observed. As the concrete strength and reinforcement ratio increased, fewer shear cracks were present along the surface of the GFRP RC beams. However, the balanced GFRP RC beam (40-\#2-0.5-I) as displayed in Fig. 18 and the under-reinforced GFRP RC beam (80-\#2-0.5-I) failed due to rupture of the tensile reinforcement and thus vertical flexural cracks were evident along the surface of the beams after impact.

From the behaviour of the GFRP RC beams under impact loading, it is evident that after being subjected to the drop hammer, beams were still in elastic range. This has to do with the beams energy absorption capacity and reserve capacity. For the four over-reinforced GFRP $\mathrm{RC}$ beams, after the first drop in the load carrying capacity, beams had substantial reserve energy $\left(E_{2}\right)$ until total failure from static testing. Damage and shear cracking caused by impact loading to GFRP RC beams 80-\#3-1.0-I and 80-\#4-2.0-I are demonstrated in Fig. 16 and Fig. 17. The reserve energy, $E_{2}$ was calculated as $949 \mathrm{~J}, 998 \mathrm{~J}, 2474 \mathrm{~J}$ and $864 \mathrm{~J}$ for GFRP RC beams 40-\#3-1.0-I, 40-\#4-2.0-I, 80-\#3-1.0-I and 80-\#4-2.0-I respectively from static testing results.

In terms of deflection, GFRP RC beams with $\rho_{f}=0.5 \%$ totally collapsed during impact and thus deflection could not be measured. For beams with $\rho_{f}=1.0 \%$ increase in the compressive strength of concrete from $40 \mathrm{MPa}$ to $80 \mathrm{MPa}$ reduced the deflection by $10 \%$, 
from $57.5 \mathrm{~mm}$ to $51.6 \mathrm{~mm}$. For $\rho_{f}=2.0 \%$, reduction was $16 \%$, from $52.3 \mathrm{~mm}$ to $43.8 \mathrm{~mm}$. Hence, mid-span deflection can be controlled using larger reinforcement ratio and higher concrete strength. Fig. 19 displays the mid-span maximum deflection and time history of the four over-reinforced GFRP RC beams under impact loading. Fig. 20 outlines the use of the high-speed camera for measuring maximum midspan deflection. As shown for GFRP RC beam 40-\#3-1.0-I, the leveller and black circular markers were used to track deflections frame by frame using image processing software. For a change in reinforcement ratio from $1.0 \%$ to $2.0 \%$, it is clear that for the GFRP RC beam with concrete strength of $80 \mathrm{MPa}$, midspan deflection reduced. For the beams with concrete strength of $40 \mathrm{MPa}$, the mid-span deflection was decreased by only $9 \%$, whereas for the beams with a concrete strength of 80 $\mathrm{MPa}$, the mid-span deflection was decreased by $15 \%$.

The strain data of one GFRP reinforcement bar was analysed at the time of maximum impact load for the six GFRP RC beams under impact loading, that is at $t=0.12 \mathrm{~s}$. Due to some complications, the strain data for the under-reinforced beam (GFRP RC beam 40-\#2-0.5-I) could not be captured. For the under-reinforced beam (GFRP RC beam 80-\#2-0.5-I), the strain in the GFRP reinforcement bar $\left(\varepsilon_{f r p}\right)$ reached a maximum value of $1.24 \%$ at $t=0.12 \mathrm{~s}$ before rupturing, lower than the mean experimental value of $1.96 \%$ (experimental tensile testing). For the over-reinforced beams with $\rho_{f}=1.0 \%$ (GFRP RC beams 40-\#3-1.0-I and 80-\#3-1.0-I) the strain in the GFRP reinforcement bars was approximately $0.95 \%$ for both beams, significantly lower than the mean rupture strain $(3.18 \%)$ obtained experimental testing. The strain in the GFRP reinforcement only reached $0.78 \%$ and $0.68 \%$ for GFRP RC beams 40-\#4-2.0-I and 40-\#4-2.0-I, respectively. This is significantly lower than the rupture strain obtained from the tensile testing, $3.30 \%$ for \#4 GFRP reinforcement bars. Hence, crushing failure occurred for the four over-reinforced GFRP RC beams, since the strain in the GFRP reinforcement was less than the rupture strain of the GFRP reinforcement. Fig. 21 portrays the dynamic strain time history of the GFRP RC beams under impact loading. It took $0.1 \mathrm{~s}$ for the drop hammer to strike the GFRP RC beams and thus dynamic strain begins at $t=0.1 \mathrm{~s}$.

The experimental dynamic moment capacity $\left(M_{d}\right)$ of the GFRP RC beams under impact loading was obtained from dynamic vertical equilibrium, using the support reaction forces, $R_{1}(t)$ and $R_{2}(t)$, impact load $I(t)$ and inertial resistance forces. The inertial 
resistance forces were assumed to act in a triangular pattern along the GFRP RC beams and thus $M_{d}$ was calculated at the mid-span using equation (2), see Fig. 22.

$$
M_{d}=\frac{2 L}{6} R_{1}(t)+\frac{I(t)}{2} \times \frac{L}{6}
$$

Fig. 23 shows the impact force and breakdown of resisting forces of GFRP RC beam 40-\#31.0-I for a 50 millisecond (ms) window (from $90 \mathrm{~ms}$ to $140 \mathrm{~ms}$ ). It is clear that the first initial contact occurred at 0.1 seconds, demonstrated by a large magnitude short duration pulse at the beginning of the impact force and inertial resistance time histories. It is evident that at this point in time, the inertia force was approximately equal to the impact force, as the dynamic support reactions were not being active during the initial contact due to the beam's inertia. A general pattern can be observed from the test results. At the initial point of contact between the beam and drop hammer $(t=0.1 \mathrm{~s})$, resistance is controlled by inertia forces. Initially, approximately $100 \%$ of the resistance is controlled by the inertia forces. But at 0.12 seconds, there is a significant change in the resistance (Fig. 23). Thus, after the initial contact ( $t \geq$ $0.11 s$ ), resistance was controlled by the GFRP RC beams flexural resisting; an average of $90 \%$ force is transferred to the supports and $10 \%$ is resisted by inertia for all impact tests on GFRP RC beams.

The relationship between dynamic moment capacity and time for GFRP RC beam 40-\#3-1.0I is shown in Fig. 24 for $t=0.1 s$ to $0.14 s$. By utilising Fig. 23 and substituting $I(t)$ and a support reaction, $R_{1}(t)$ into equation (2), $M_{d}$ could be calculated. $M_{d}$ is roughly constant for a short time interval and thus the average dynamic moment, $M_{d} \approx 16 \mathrm{kNm}$ for the GFRP RC beam 40-\#3-1.0-I.

Table 5 summaries the experimental dynamic moment capacities $\left(M_{d}\right)$ and experimental moment capacities from static testing $\left(M_{\text {exp }}\right)$ of the GFRP RC beams under impact loading. Data could not be captured (including $M_{d}$ ) for the GFRP RC beams 40-\#2-0.5-I and 80-\#2S0.5-I since they collapsed during testing. For the four over-reinforced GFRP RC beams under impact loading, the ratio of the experimental dynamic moment capacity, $M_{d}$ to the experimental moment capacity, $M_{n}$, that is $M_{d} / M_{\exp }$ was greater than one. A mean value of $M_{d} / M_{n}=1.15$ was calculated and this ratio is defined as the dynamic amplification factor, which describes the enhancement of the beam's resistance due to impact loading. The dynamic amplification factor also indicates that the four GFRP RC beams have additional 
reserve capacity when subjected to impact loading which can be used for designing of GFRP $\mathrm{RC}$ beams subjected to impact loads.

For comparative purposes, a steel RC beam was previously tested under impact loading with an impact energy of $1177 \mathrm{~J}$ with concrete strength and reinforcement ratio of $40 \mathrm{MPa}$ and $1.2 \%$, respectively. By comparing this beam with the GFRP RC beam 40-\#3-1.0-I, it was observed that mid-span deflection was significantly higher for the GFRP RC beam, 47\% increase from $39.1 \mathrm{~mm}$ to $57.5 \mathrm{~mm}$ (Fig. 25). However, the steel RC beam, designed as under-reinforced, showed different mode of response compared to the GFRP RC beam. Flexural cracks are evident along the span of the RC beam, with very minor concrete crushing on the impact zone as shown in Fig. 26 compared to a "shear plug" failure for the GFRP RC beam. This could be attributed to the low velocity of the drop hammer $(1.98 \mathrm{~m} / \mathrm{s})$ due to the $200 \mathrm{~mm}$ height, which was reiterated by Ohnuma et al [23] who showed at lower velocity's, beams were flexural critical. Whereas the GFRP RC beam velocity was $4.85 \mathrm{~m} / \mathrm{s}$, increase of velocity of $145 \%$. The steel RC beams capacity was roughly $30 \mathrm{kN}$ from $t=$ 0 to $0.1 \mathrm{~s}$ as shown in Fig. 27 compared to $33 \mathrm{kN}$ for the GFRP RC beam 40-\#3-1.0-I for $t \geq 0.11 s$ (Fig. 23).

\section{CONCLUSIONS}

A successful experimental program of twelve GFRP RC beams under static and impact loading has been presented and discussed highlighting the effectiveness of the use of GFRP reinforcing bars in beams. The test results show the representative behaviour of GFRP RC beams under static and impact loading. The behaviour of GFRP RC beams with varying reinforcement ratio and concrete strengths have been investigated. Observations and experimental data analyses have led to the following conclusions:

1. The failure mode of GFRP RC beams can be accurately predicted from sectional analysis used for traditional $\mathrm{RC}$ beams. The ratio of the beam reinforcement to the calculated balanced reinforcement $\left(\rho_{f} / \rho_{f b}\right)$ can be used as an indicator for the failure mode of the GFRP RC beams. Concrete crushing on the top surface occurred for GFRP RC beams reinforced with more than the balanced reinforcement. While, for 
the GFRP RC beams reinforced with lower than the balanced reinforcement, rupture of the GFRP reinforcement bars governed.

2. The load-deflection behaviour of the normal strength and high strength concrete GFRP RC beams under static loading displayed a bi-linear response, with the initial section of the response indicating an uncracked behaviour of the beam. The second part of the response indicated the cracked behaviour of the GFRP RC beam. Also, GFRP RC beams designed as over-reinforced with $1.0 \%$ and $2.0 \%$ reinforcement ratio showed signs of reserve capacity or "ductility" prior to total failure.

3. Effect of concrete strength was shown to be more prominent in reducing midspan deflection and increasing post-cracking bending stiffness. Increasing the concrete strength for higher reinforcement ratio $(2.0 \%)$ showed reduction in the mid-span deflection by $21 \%$ compared to only $7.0 \%$ for a reinforcement ratio of $1.0 \%$. However, increasing concrete strength from normal strength to high strength showed minimal effect on experimental moment capacity, regardless of the reinforcement ratio. Post cracking bending stiffness increased $25 \%$ and $23 \%$ for $1.0 \%$ and $2.0 \%$ reinforcement ratio, respectively, for an increase in concrete strength from 40 to 80 MPa. The post-cracking bending stiffness was shown to be higher for the overreinforced GFRP RC with higher strength concrete for the same reinforcement ratio.

4. Resistance of GFRP RC beams under impact loading have been observed to be controlled by inertia forces at first contact before beam flexural behaviour starts contributing to resisting the impact load.. Thus, the geometrical properties of the beam, as well as the total mass are major factors in resisting dynamic forces.

5. Under impact loading, regardless of the shear capacity of the GFRP RC beams, the over-reinforced beams have been observed to experience minor inclined shear cracking and crushing of concrete cover around the impact zone at approximately 45 degree angles, resulting in a "shear plug" type of failure. Whereas, the GFRP RC beams under static loading were shown to be flexural critical. Thus, the shear behaviour of flexure-critical GFRP RC beams must be considered in dynamic modelling or in designing beams for impact loads.

6. Dynamic amplification factor was shown to be on average $15 \%$ higher for the GFRP $\mathrm{RC}$ beams under impact loading compared to static loading. 
Steel reinforcement was shown to be more prominent in controlling midspan deflection, a decrease of $32 \%$ compared to GFRP RC beam 40-\#3-1.0-S. However, dynamic beam capacities were similar, 10\% increase in GFRP RC beam 40-\#3-1.0-S (33 kN compared to 30 $\mathrm{kN})$.

\section{REFERENCES}

[1] Attari N, Amziane S, Chemrouk M. Flexural strengthening of concrete beams using CFRP, GFRP and hybrid FRP sheets. Construction and Building Materials 2012;37(0):74657.

[2] Smith ST, Hu S, Kim SJ, Seracino R. FRP-strengthened RC slabs anchored with FRP anchors. Engineering Structures 2011;33(4):1075-87.

[3] Li G, Kidane S, Su-Seng P, Helms JE, Stubblefield MA. Investigation into FRP repaired RC columns. Composite Structures 2003;62(1):83-9.

[4] Alsayed SH. Flexural behaviour of concrete beams reinforced with GFRP bars. Cement and Concrete Composites 1997;20(1):1-11.

[5] Noel M, Soudki, K. Estimation of the crack width and deformation of FRP-reinforced concrete flexural members with and without transverse shear reinforcement. Engineering Structures 2014;59(0):393-98.

[6] Kalpana VG, Subramanian K. Behavior of concrete beams reinforced with GFRP bars. Journal of Reinforced Plastics and Composites 2011;30(23):1915-22.

[7] Ashour AF, Habeeb MN. Continuous concrete beams reinforced with CFRP bars. Proceedings of the Institution of Civil Engineers: Structures and Buildings 2008;161(6):34957.

[8] Toutanji HA, Saafi M. Flexural behavior of concrete beams reinforced with glass fiberreinforced polymer (GFRP) bars. ACI Structural Journal 2000;97(5):712-19.

[9] ACI Committee 440. Guide for the design and construction of structural concrete reinforced with FRP Bars. Farmington Hills (MI): American Concrete Institute; 2006.

[10] Benmokrane B, Zhang B, Chennouf A. Tensile properties and pullout behaviour of AFRP and CFRP rods for grouted anchor applications. Construction and Building Materials 2000;14(3):157-70. 
[11] Ascione L, Mancusi G, Spadea S. Flexural behaviour of concrete beams reinforced with GFRP bars. Strain 2010;46(5):460-69.

[12] Rafi MM, Nadjai A, Ali F. Experimental testing of concrete beams reinforced with carbon FRP bars 2007. Journal of Composite Materials 2007;41(22):2657-73.

[13] Andermatt MF, Lubell AS. Behavior of concrete deep beams reinforced with internal fiber-reinforced polymer-experimental study. ACI Structural Journal 2013;110(4):585-94.

[14] Kobraei M, Jumaat MZ, Shafigh P. An experimental study on shear reinforcement in RC beams using CFRP-bars. Scientific Research and Essays 2011;6(16):3447-60.

[15] Ashour AF, Family M. Tests of concrete flanged beams reinforced with CFRP bars. Magazine of Concrete Research 2006; 58(9):627-39.

[16] Rafi MM, Nadjai A. A suggested model for European code to calculate deflection of FRP reinforced concrete beams. Magazine of Concrete Research 2011; 63(3):197-214.

[17] Abdalla HA. Evaluation of deflection in concrete members reinforced with fibre reinforced polymer (FRP) bars. Composite Structures 2002; 56(1):63-71.

[18] Lau D, Pam HJ. Experimental study of hybrid FRP reinforced concrete beams. Engineering Structures 2010; 32(12):3857-65.

[19] Yoo DY, Banthia N, Yoon YS. Flexural behavior of ultra-high-performance fiberreinforced concrete beams reinforced with GFRP and steel bars. Engineering Structures 2016; 15(111): 246-62

[20]El-Nemr A, Ahmed EA, Benmokrane B. Flexural Behaviour and Serviceability of Normal- and High-Strength Concrete Beams Reinforced with Glass Fibre-Reinforced Polymer Bars. ACI Structural Journal 2013;110(6):1077-88.

[21] Fujikake K, Li B, Soeun S. Impact response of reinforced concrete beam and its analytical evaluation. Journal of Structural Engineering 2009;135(8):938-50.

[22] Saatchi S, Vecchio FJ. Effects on shear mechanisms on impact behavior of reinforced concrete beams. ACI Structural Journal 2009;106(1):78-86.

[23] Ohnuma H, Ito C, Nomachi SG. Dynamic response and local rupture of reinforced concrete beam and slab under impact loading. In: Transaction of the $8^{\text {th }}$ international conference on structural mechanics in reactor technology (SMiRT 8), Brussels, Belgium, August 19-23; 1985.

[24] American Society for Testing and Materials (ASTM). Standard Testing Methods and Definitions for Mechanical Testing of Steel Products. A370-14. West Conshohocken (PA); 2014. 
[25] American Society for Testing and Materials (ASTM). Standard Test Method for Tensile Properties of Fiber Reinforced Polymer Matrix Composite Bars. D7205 / D7205M. West Conshohocken (PA); 2006(11). 


\section{LIST OF TABLES}

Table 1. Tensile Test Results of GFRP Bars

Table 2. Details of Test Specimens

Table 3. Static Test Results of GFRP RC Beams

Table 4. Comparative Analysis of Design and Experimental Moment Capacities of GFRP RC Beams under Static Loading

Table 5. Dynamic Amplification Factors for GFRP RC Beams 


\section{LIST OF FIGURES}

Fig. 1. Tensile Test Specimen

Fig. 2. Failure of Tensile Test Specimen 4 \#3 (Table 1)

Fig. 3. Stress-Strain Curve for Specimen 9 \#4 (Table 1)

Fig. 4. Details of GFRP RC beams

(a) Cross-section of GFRP RC Beams

(b) Side view of GFRP RC beams

Fig. 5. Static Testing Apparatus

Fig. 6. Loading Configuration for Static Testing

Fig. 7. Impact Testing Apparatus

Fig. 8. Balanced Failure of GFRP RC Beam 40-\#2-0.5-S under Static Loading

Fig. 9. Flexural Response with Concrete Crushing of GFRP RC Beam 40-\#3-1.0-S under Static Loading

Fig. 10. Effect of Reinforcement Ratio and Concrete Strength on Beam Moment Capacity

Fig. 11. Effect of Reinforcement Ratio and Concrete Strength on Beam Mid-Span Deflection

Fig. 12. Effect of Reinforcement Ratio and Concrete Strength on Bending Stiffness

Fig 13. Energy Absorption Capacity $\left(E_{1}\right.$ and $\left.E_{2}\right)$ Calculation

Fig. 14. Load-Deflection Relationship of GFRP RC Beams

Fig. 15. Energy Absorption Capacity of GFRP RC Beams under Static Loading

Fig. 16. Shear Plug of GFRP RC Beam 80-\#3-1.0-I under Impact Loading

Fig. 17. Shear Plug of GFRP RC Beam 80-\#4-2.0-I under Impact Loading

Fig. 18. Balanced Failure of GFRP RC Beam 40-\#2-0.5-I under Impact Loading

Fig. 19. Dynamic Mid-Span Deflections of GFRP RC Beams from Image Processing of High-Speed Video Recordings

Fig. 20. High Speed Camera at Mid-Span Deflection of GFRP RC Beam 40-\#4-2.0-I under Impact Loading

Fig. 21. Dynamic Strain Time History of GFRP RC beams

Fig. 22. Free Body Diagram for Dynamic Moment Capacity Calculation

Fig. 23. Breakdown of Resisting Forces for GFRP RC Beam 40-\#3-1.0-I under Impact Loading

Fig. 24. Average Dynamic Moment for GFRP RC Beam 40-\#3-1.0-I under Impact Loading 
Fig. 25. Comparative Analysis of Mid-Span Deflection

Fig. 26. Steel RC Beam after Impact Loading

Fig. 27. Load-Time History of Steel RC Beam 


\section{TABLES}

Table 1. Tensile Test Results of GFRP Bars

\begin{tabular}{|c|c|c|c|c|c|c|c|}
\hline $\begin{array}{c}\text { Specimen } \\
\text { (Designation) }\end{array}$ & $\begin{array}{c}\text { Diameter, } \varnothing \\
(\mathbf{m m})\end{array}$ & $\begin{array}{c}L_{a} \\
(\mathrm{~mm})\end{array}$ & $\begin{array}{c}L \\
(\mathbf{m m})\end{array}$ & $\begin{array}{c}L_{t o t} \\
(\mathrm{~mm})\end{array}$ & $\begin{array}{c}\boldsymbol{f}_{\boldsymbol{u}} \\
(\mathbf{M P a})\end{array}$ & $\begin{array}{l}\varepsilon_{f u} \\
(\%)\end{array}$ & $\begin{array}{c}E_{f} \\
(\mathbf{G P a})\end{array}$ \\
\hline $1(\# 2)$ & 6.35 & 150 & 380 & 680 & 740 & 1.93 & 38.3 \\
\hline $2(\# 2)$ & 6.35 & 150 & 380 & 680 & 718 & 1.94 & 37.1 \\
\hline $3(\# 2)$ & 6.35 & 150 & 380 & 680 & 739 & 2.00 & 37.0 \\
\hline \multicolumn{5}{|c|}{ Mean } & 732 & 1.96 & 37.5 \\
\hline $4(\# 3)$ & 9.53 & 400 & 200 & 1000 & 1801 & 3.36 & 53.7 \\
\hline $5(\# 3)$ & 9.53 & 400 & 200 & 1000 & 1692 & 2.97 & 57.0 \\
\hline $6(\# 3)$ & 9.53 & 400 & 200 & 1000 & 1800 & 3.21 & 56.0 \\
\hline \multicolumn{5}{|c|}{ Mean } & 1764 & 3.18 & 55.6 \\
\hline 7 (\#4) & 12.7 & 400 & 200 & 1000 & 1642 & 3.43 & 47.9 \\
\hline 8 (\#4) & 12.7 & 400 & 200 & 1000 & 1605 & 3.27 & 49.1 \\
\hline $9(\# 4)$ & 12.7 & 400 & 200 & 1000 & 1567 & 3.21 & 48.9 \\
\hline \multicolumn{5}{|c|}{ Mean } & 1605 & 3.30 & 48.6 \\
\hline
\end{tabular}


Table 2. Details of Test Specimens

\begin{tabular}{|c|c|c|c|c|c|}
\hline Beam & $\begin{array}{c}\boldsymbol{A}_{\boldsymbol{f}} \\
\left(\mathbf{m m}^{2}\right)\end{array}$ & $\begin{array}{c}\boldsymbol{M}_{\boldsymbol{n}} \\
(\mathbf{k N . ~ m})\end{array}$ & $\boldsymbol{\rho}_{\boldsymbol{f}} / \boldsymbol{\rho}_{\boldsymbol{f} \boldsymbol{b}}$ & $\begin{array}{c}\boldsymbol{d} \\
(\mathbf{m m})\end{array}$ & Design Failure Mode \\
\hline $\mathbf{4 0 - \# 2 - 0 . 5 - S}$ & 63.4 & 5.70 & 0.90 & 127.8 & Balanced \\
\hline $\mathbf{4 0 - \# 3 - 1 . 0 - S}$ & 142.6 & 9.93 & 7.53 & 126.2 & Concrete Crushing \\
\hline $\mathbf{4 0 - \# 4 - 2 . 0 - S}$ & 253.4 & 11.6 & 12.7 & 124.7 & Concrete Crushing \\
\hline $\mathbf{4 0 - \# 2 - 0 . 5 - I}$ & 63.4 & 5.68 & 0.86 & 127.8 & Balanced \\
\hline $\mathbf{4 0 - \# 3 - 1 . 0 - I}$ & 142.6 & 10.1 & 7.27 & 126.2 & Concrete Crushing \\
\hline $\mathbf{4 0 - \# 4 - 2 . 0 - I}$ & 253.4 & 11.8 & 12.4 & 124.7 & Concrete Crushing \\
\hline $\mathbf{8 0 - \# 2 - 0 . 5 - S}$ & 63.4 & 5.68 & 0.70 & 127.8 & GFRP Rupture \\
\hline $\mathbf{8 0 - \# 3 - 1 . 0 - S}$ & 142.6 & 11.5 & 5.65 & 126.2 & Concrete Crushing \\
\hline $\mathbf{8 0 - \# 4 - 2 . 0 - S}$ & 253.4 & 13.4 & 10.2 & 124.7 & Concrete Crushing \\
\hline $\mathbf{8 0 - \# 2 - 0 . 5 - I}$ & 63.4 & 5.68 & 0.68 & 127.8 & GFRP Rupture \\
\hline $\mathbf{8 0 - \# 3 - 1 . 0 - I}$ & 142.6 & 11.6 & 5.77 & 126.2 & Concrete Crushing \\
\hline $\mathbf{8 0 - \# 4 - 2 . 0 - I}$ & 253.4 & 13.6 & 9.81 & 124.7 & Concrete Crushing \\
\hline
\end{tabular}

Table 3. Static Test Results of GFRP RC Beams

\begin{tabular}{|c|c|c|c|c|c|c|c|c|}
\hline $\begin{array}{c}\text { Beam } \\
\text { (Failure Mode) }\end{array}$ & $\begin{array}{c}\boldsymbol{P}_{\boldsymbol{c r}} \\
(\mathbf{k N})\end{array}$ & $\begin{array}{c}\boldsymbol{P}_{\boldsymbol{u}} \\
(\mathbf{k N})\end{array}$ & $\begin{array}{c}\boldsymbol{M}_{\boldsymbol{u}} \\
(\mathbf{k N m})\end{array}$ & $\begin{array}{c}\Delta_{\max } \\
(\mathbf{m m})\end{array}$ & $\begin{array}{c}\boldsymbol{\varepsilon}_{\text {frp.avg }} \\
(\%)\end{array}$ & $\boldsymbol{\varepsilon}_{\boldsymbol{c . a v g}}$ & $\begin{array}{c}\boldsymbol{E}_{\mathbf{1}} \\
(\mathrm{J})\end{array}$ & $\begin{array}{c}\boldsymbol{E}_{\mathbf{2}} \\
(\mathrm{J})\end{array}$ \\
\hline $\begin{array}{c}\text { 40-\#2-0.5-S } \\
\text { (Balanced Failure) }\end{array}$ & 3.0 & 13.8 & 4.60 & 52.2 & $*$ & 0.0014 & 435 & 0 \\
\hline $\begin{array}{c}\text { 40-\#3-1.0-S } \\
\text { (Concrete Crushing) }\end{array}$ & 5.0 & 39.2 & 13.1 & 60.4 & 1.2 & 0.0029 & 1373 & 949 \\
\hline $\begin{array}{c}\text { 40-\#4-2.0-S } \\
\text { (Concrete Crushing) }\end{array}$ & 5.8 & 49.7 & 16.6 & 59.9 & 0.98 & 0.0033 & 1790 & 998 \\
\hline $\begin{array}{c}\text { 80-\#2-0.5-S } \\
\text { (GFRP Rupture) }\end{array}$ & 3.6 & 15.5 & 5.17 & 54.5 & $*$ & 0.001 & 518 & 0 \\
\hline $\begin{array}{c}\text { 80-\#3-1.0-S } \\
\text { (Concrete Crushing) }\end{array}$ & 5.9 & 42.6 & 14.2 & 56.3 & $*$ & 0.0022 & 1350 & 2474 \\
\hline $\begin{array}{c}\text { 80-\#4-2.0-S } \\
\text { (Concrete Crushing) }\end{array}$ & 5.7 & 49.5 & 16.5 & 47.3 & 0.93 & 0.0027 & 1292 & 864 \\
\hline
\end{tabular}

* Data not captured. 
where, $P_{c r}=$ cracking load, $P_{u}=$ experimental load carrying capacity, equal to the first drop in load carrying capacity for over-reinforced GFRP RC beams, $M_{u}=$ experimental moment capacity, $\Delta_{\max }=$ experimental maximum mid-span deflection, $\varepsilon_{f r p . a v g}=$ average strain for the two strain gauges connected to the GFRP tensile reinforcement and $\varepsilon_{\text {c.avg }}=$ average concrete strain on top surface of GFRP RC beams

Table 4. Comparative Analysis of Design and Experimental Moment Capacities of GFRP RC Beams under Static Loading

\begin{tabular}{|c|c|c|c|}
\hline Beam & $\boldsymbol{M}_{\boldsymbol{u}}$ & $\boldsymbol{M}_{\boldsymbol{n}}$ & $\frac{\boldsymbol{M}_{\boldsymbol{n}}}{\boldsymbol{M}_{\boldsymbol{u}}}$ \\
& $(\mathbf{k N m})$ & $(\mathbf{k N m})$ & \\
\hline 40-\#2-0.5-S & 4.60 & 5.70 & 1.24 \\
\hline 40-\#3-1.0-S & 13.1 & 9.93 & 0.76 \\
\hline 40-\#4-2.0-S & 16.6 & 11.6 & 0.70 \\
\hline 80-\#2-0.5-S & 5.17 & 5.68 & 1.10 \\
\hline 80-\#3-1.0-S & 14.2 & 11.5 & 0.80 \\
\hline 80-\#4-2.0-S & 16.5 & 13.4 & 0.81 \\
\hline
\end{tabular}

Table 5. Dynamic Amplification Factors for GFRP RC Beams

\begin{tabular}{|c|c|c|c|}
\hline Beam & $\begin{array}{c}M_{d}(\mathrm{kNm}) \\
\text { Dynamic }\end{array}$ & $\begin{array}{c}M_{u}(\mathrm{kNm}) \\
\text { Static }\end{array}$ & $\frac{M_{d}}{M_{u}}$ \\
\hline 40-\#2-0.5-I & $*$ & 4.60 & $*$ \\
\hline 40-\#3-1.0-I & 16 & 13.1 & 1.22 \\
\hline 40-\#4-2.0-I & 17 & 16.6 & 1.02 \\
\hline 80-\#2-0.5-I & $*$ & 5.17 & $*$ \\
\hline 80-\#3-1.0-I & 16 & 14.2 & 1.13 \\
\hline 80-\#4-2.0-I & 20 & 16.5 & 1.21 \\
\hline \multicolumn{3}{|c|}{ Mean } & 1.15 \\
\hline
\end{tabular}

* Data not captured 


\section{FIGURES}

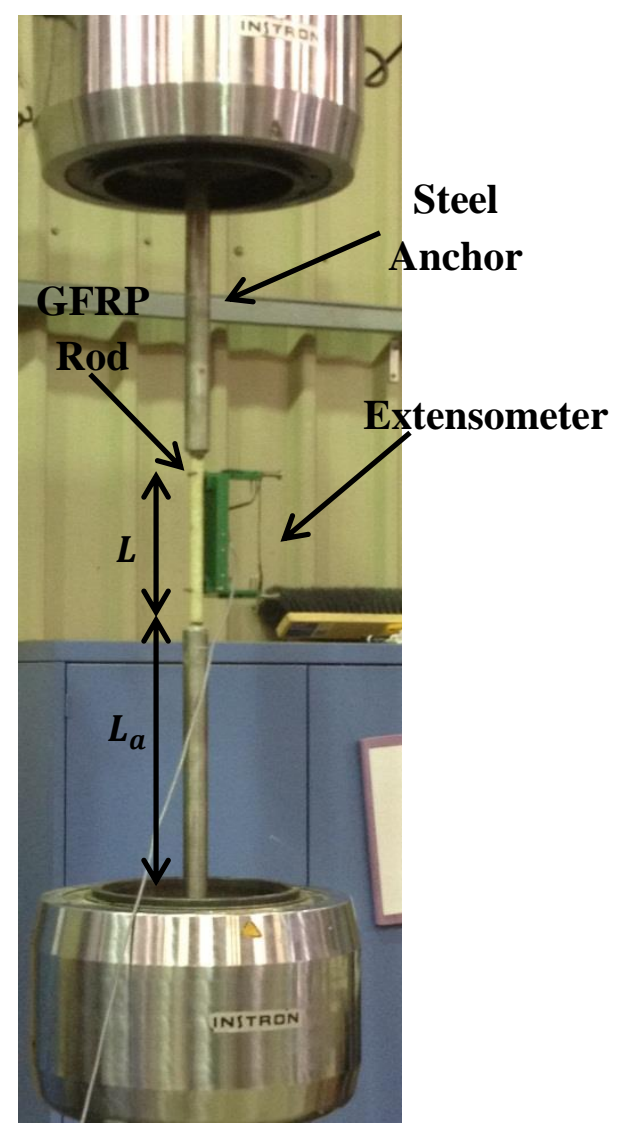

Fig. 1. Tensile Test Specimen 


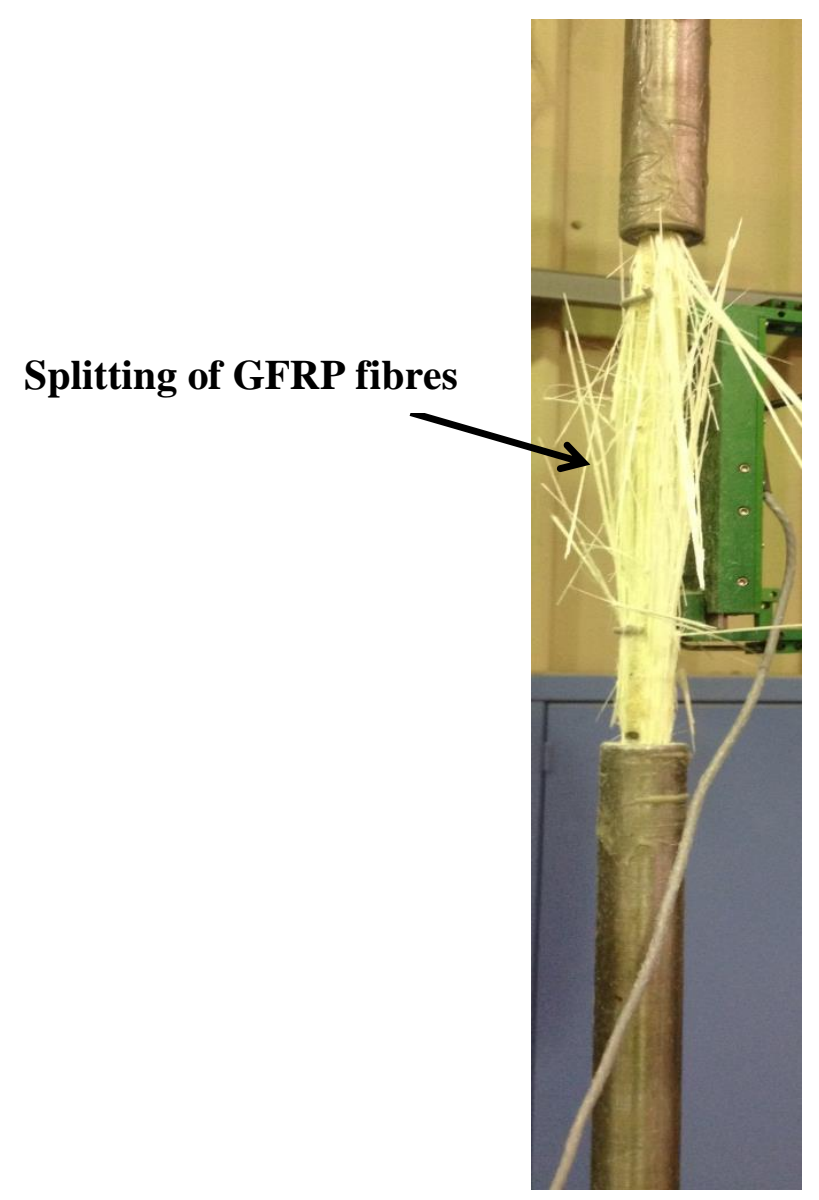

Fig. 2. Failure of Tensile Test Specimen 4 \#3 (Table 1)

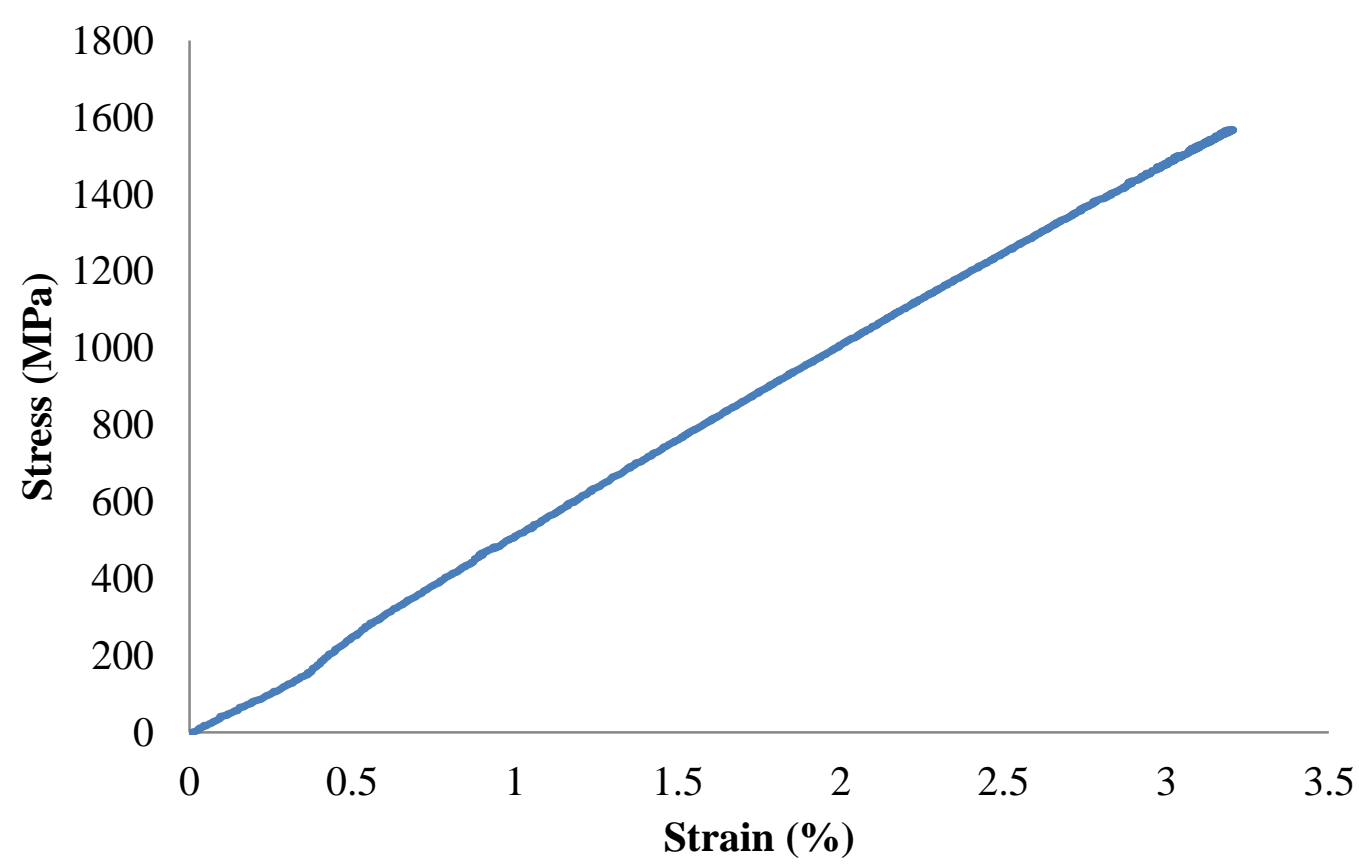

Fig. 3. Stress-Strain Curve for Specimen 9 \#4 (Table 1) 


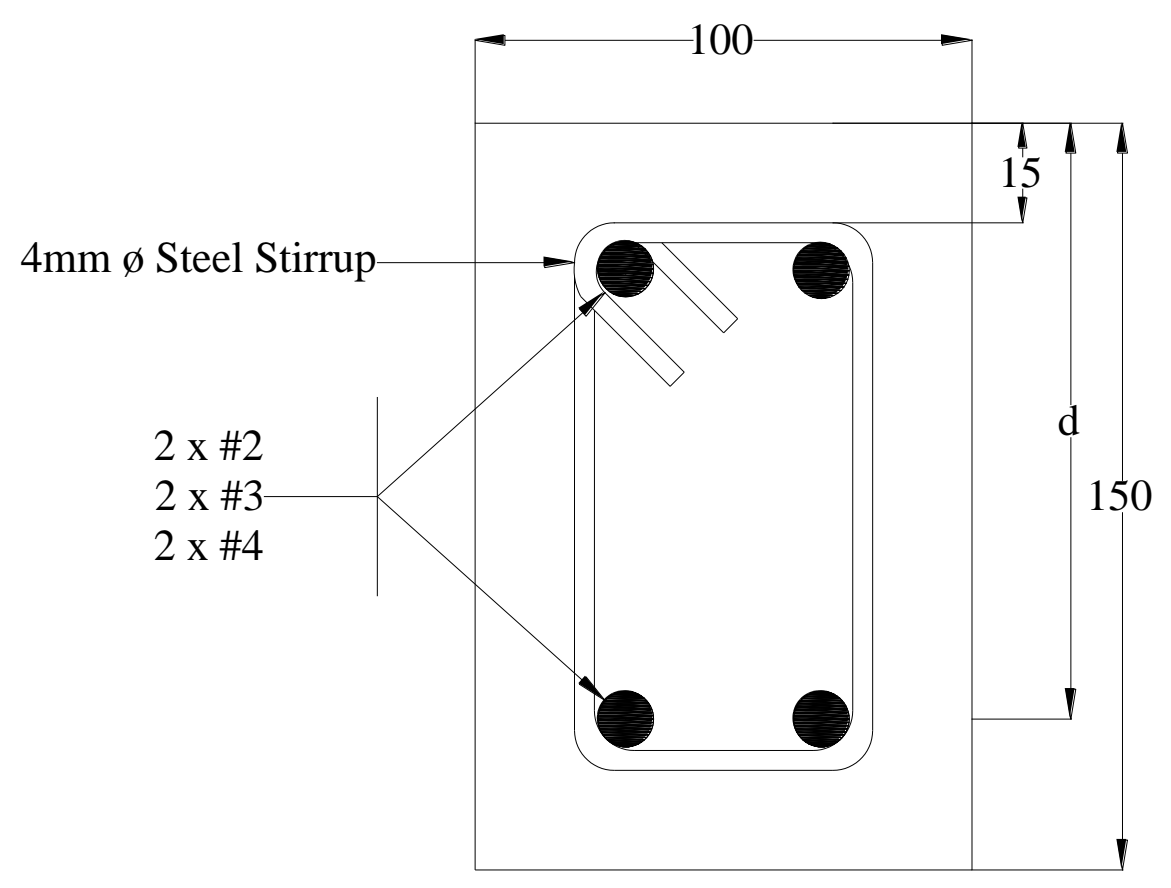

(a) Cross-section of GFRP RC Beams

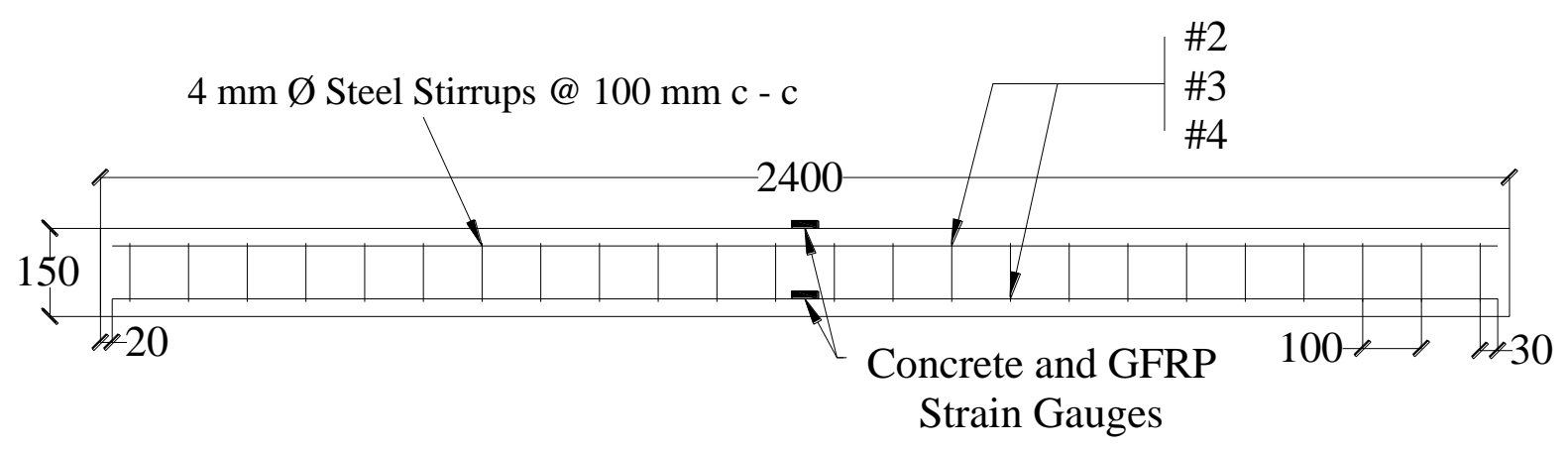

(b) Side view of GFRP RC beams

Fig. 4. Details of GFRP RC beams 


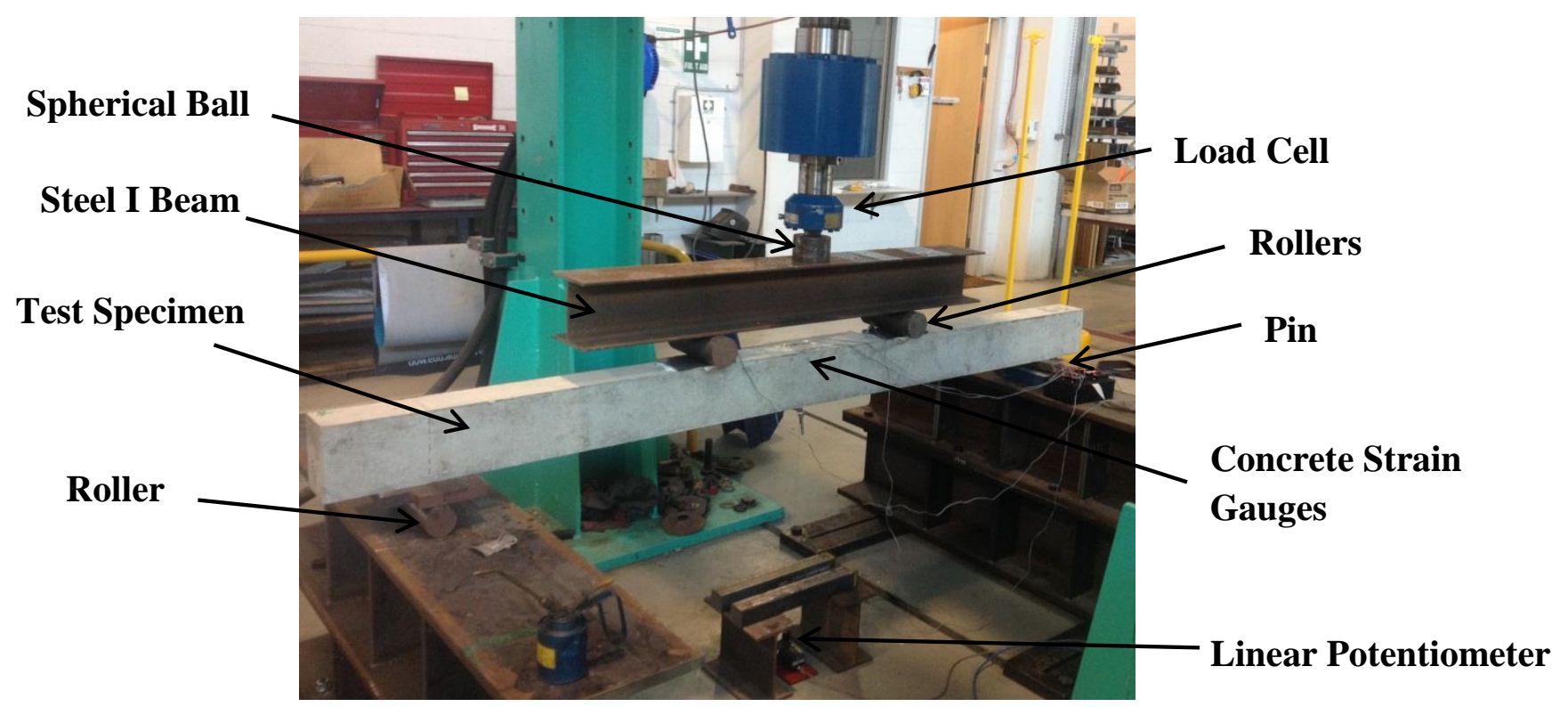

Fig. 5. Static Testing Apparatus

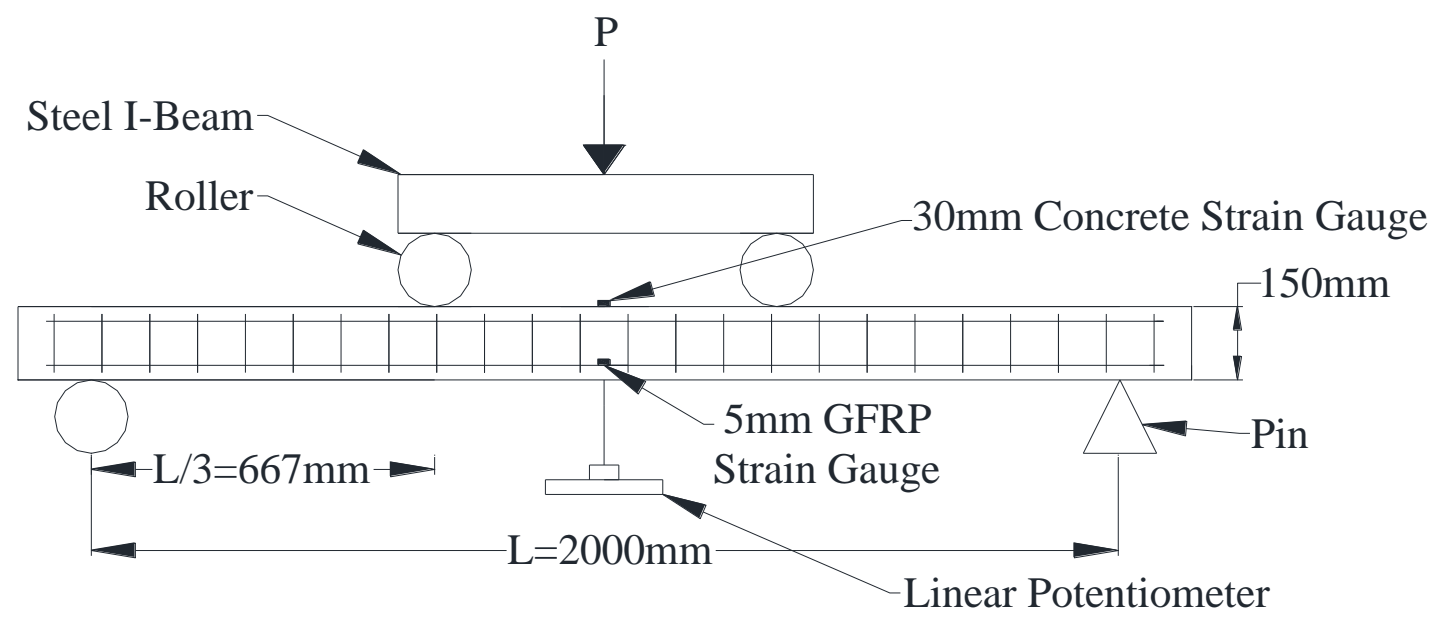

Fig. 6. Loading Configuration for Static Testing 


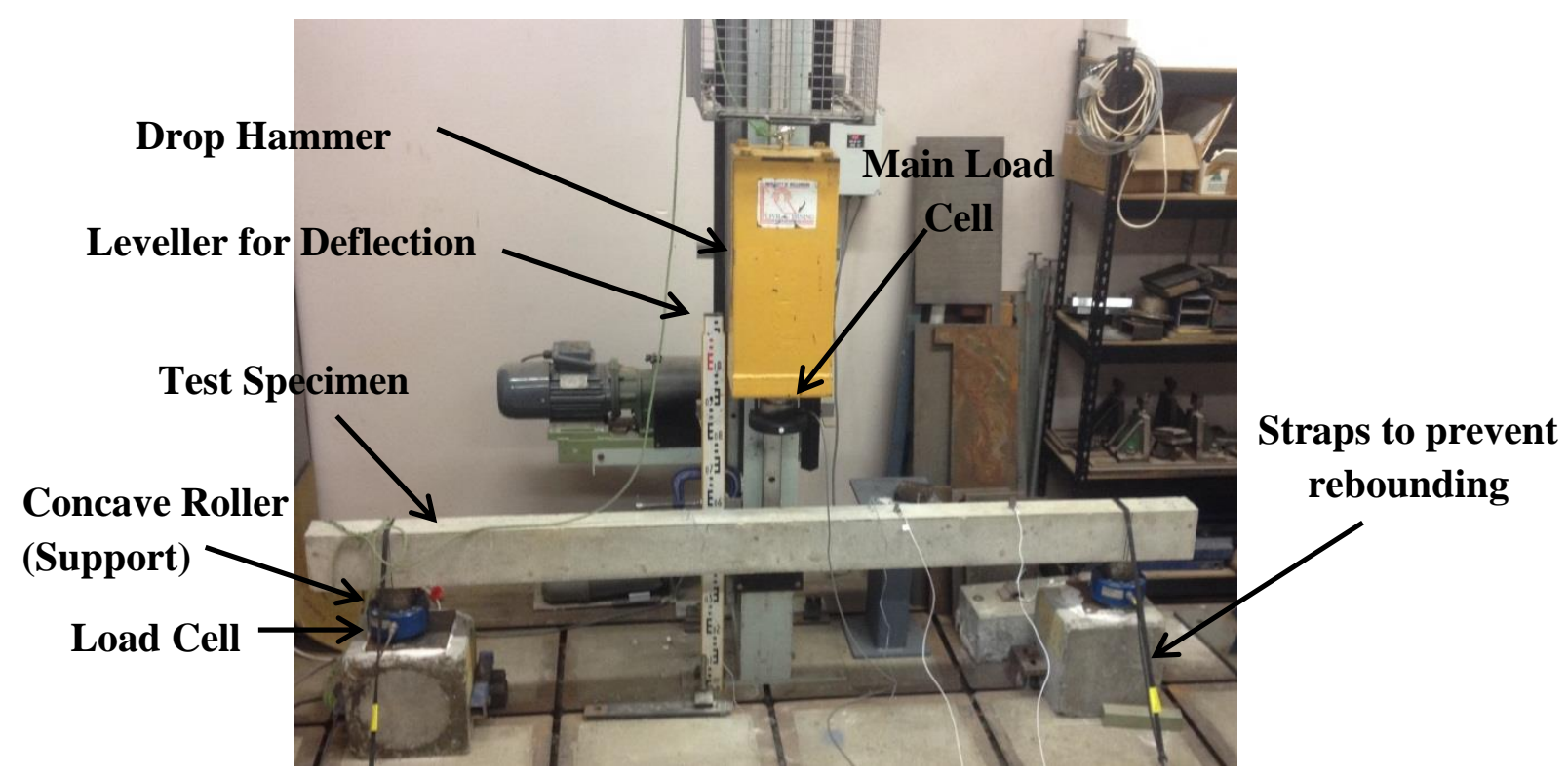

Fig. 7. Impact Testing Apparatus

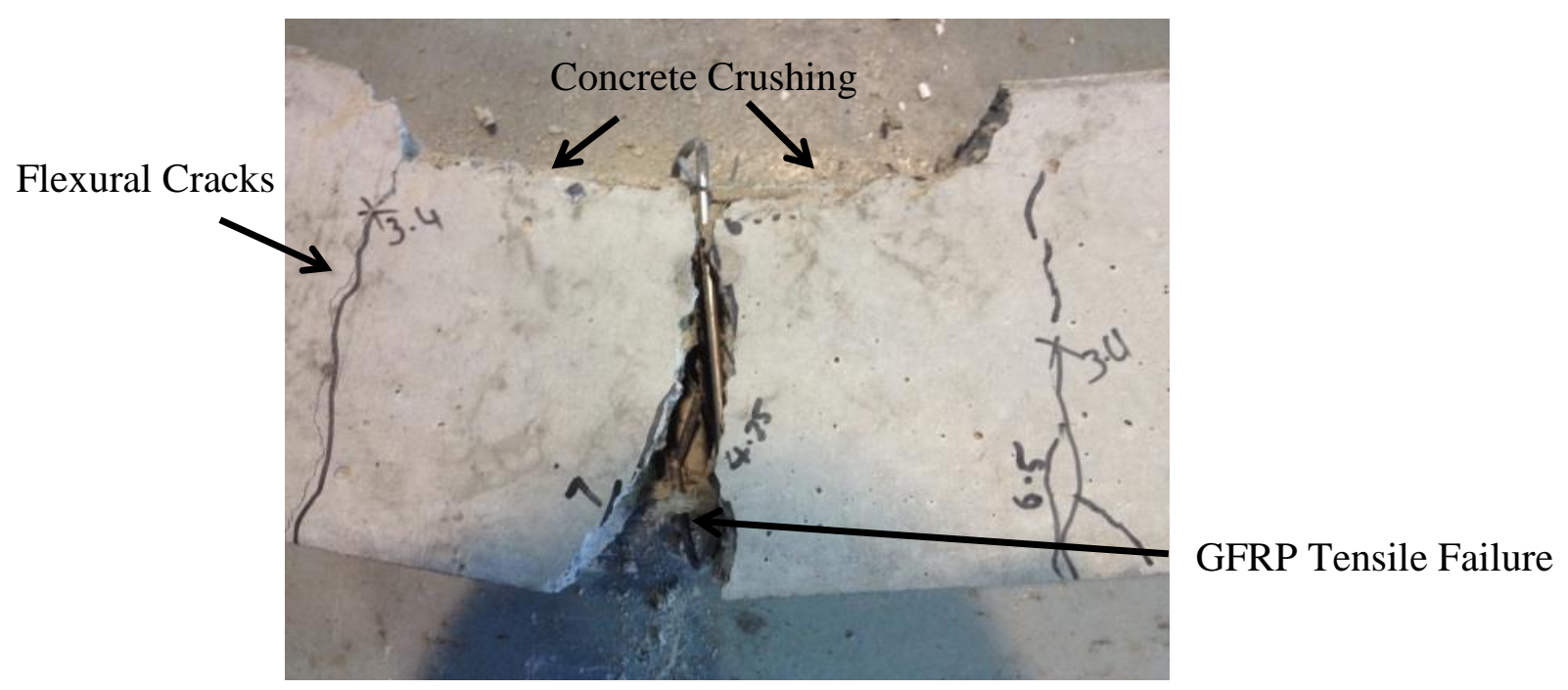

Fig. 8. Balanced Failure of GFRP RC Beam 40-\#2-0.5-S under Static Loading 


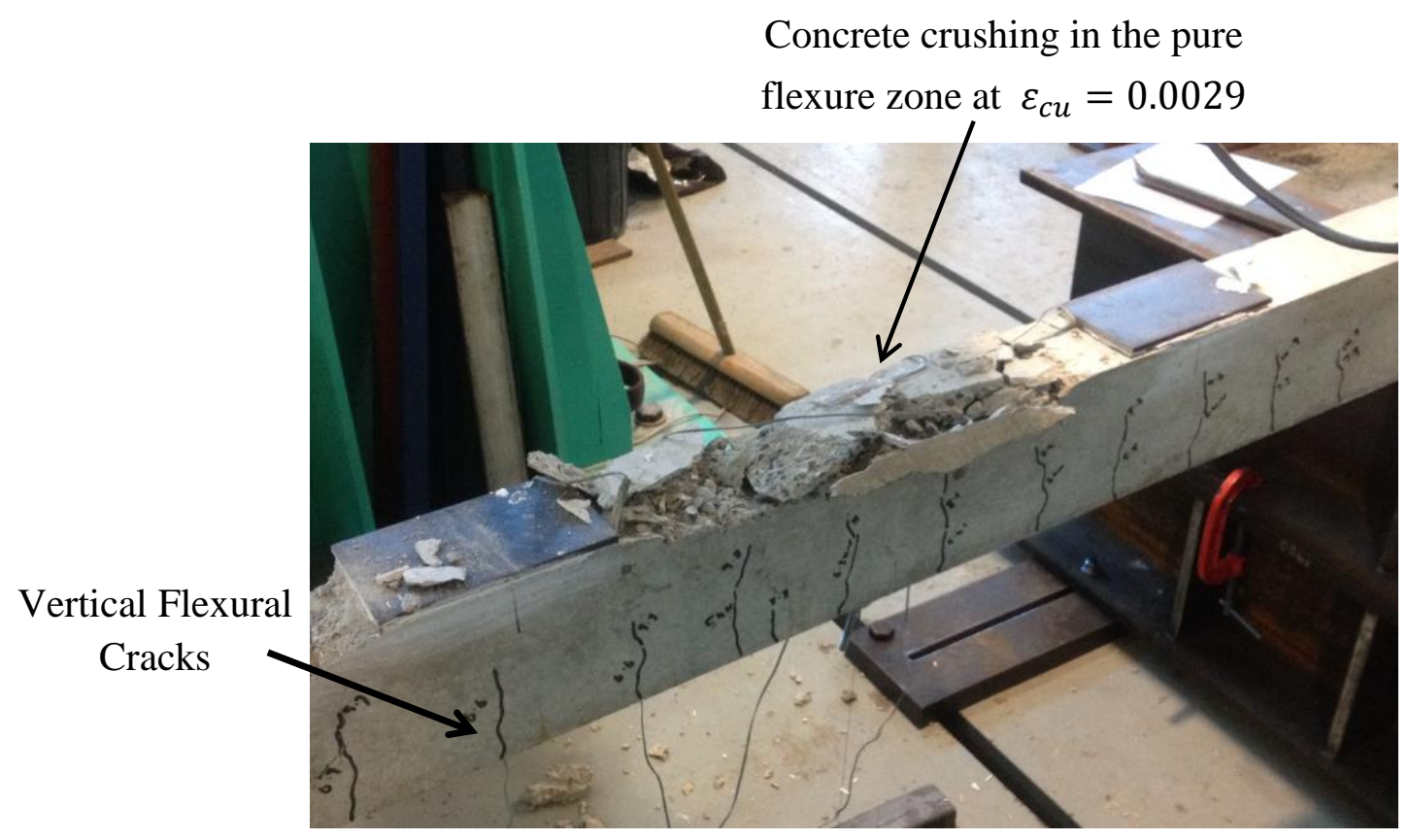

Fig. 9. Flexural Response with Concrete Crushing of GFRP RC Beam 40-\#3-1.0-S under Static Loading

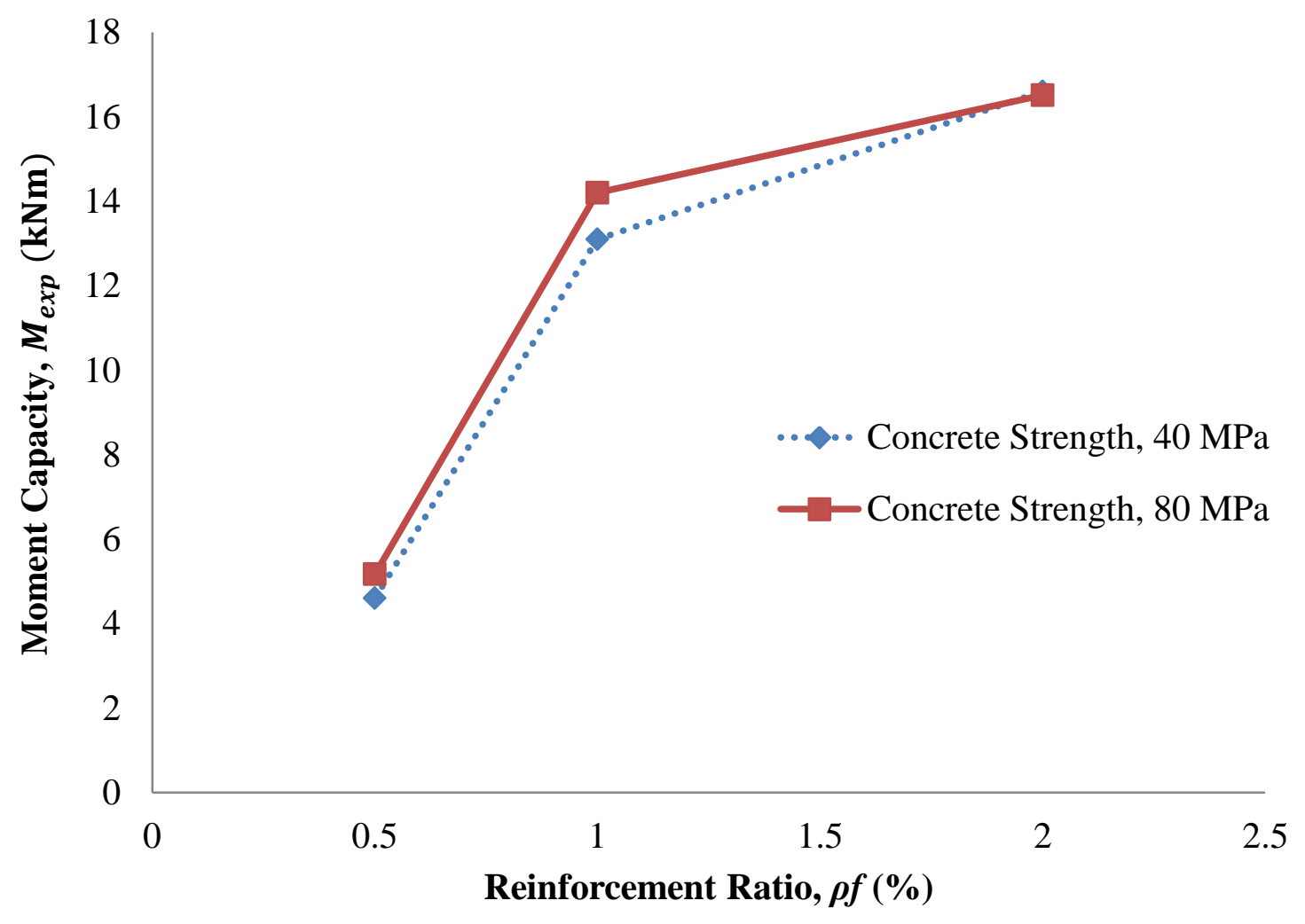

Fig. 10. Effect of Reinforcement Ratio and Concrete Strength on Beam Moment Capacity 


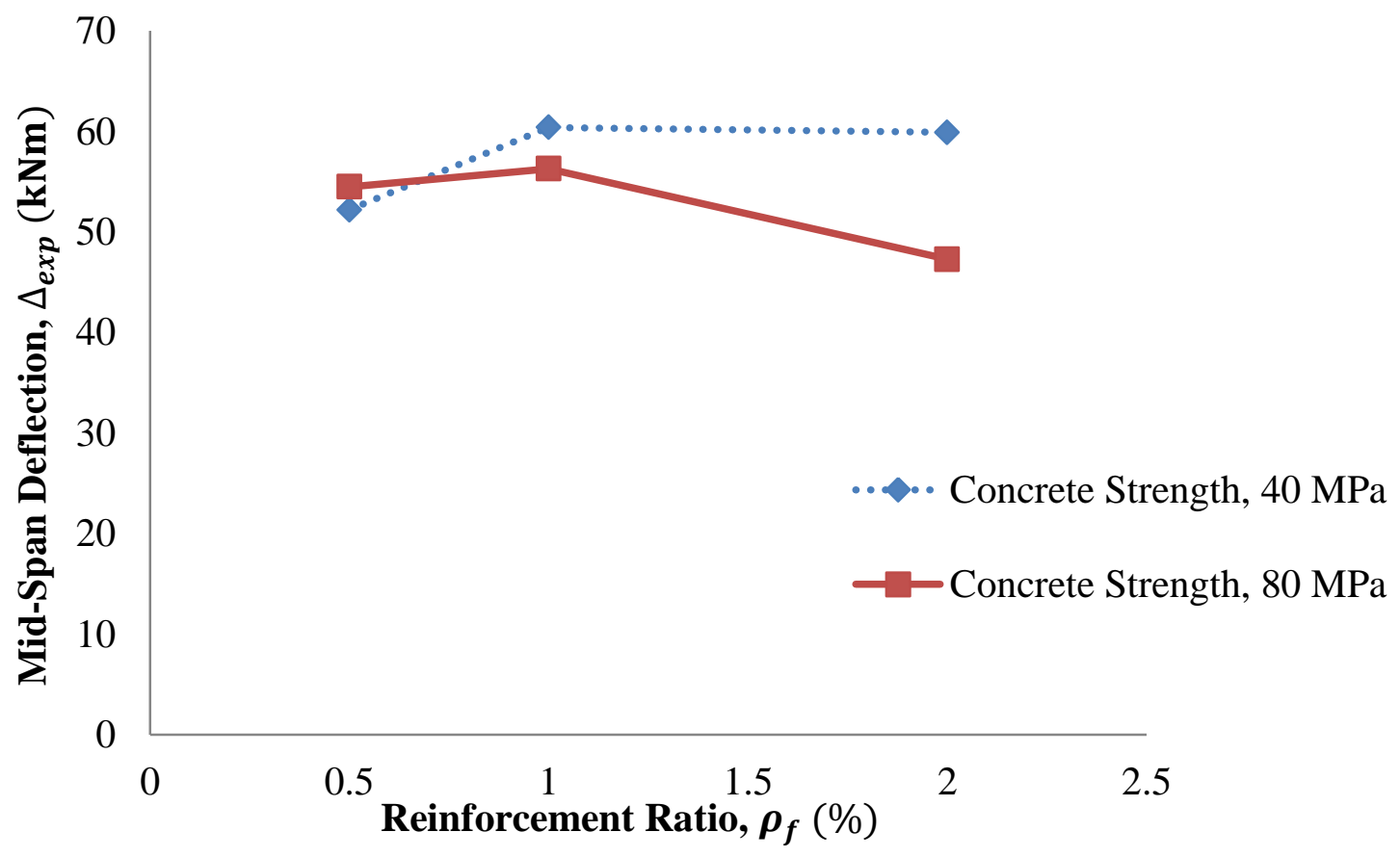

Fig. 11. Effect of Reinforcement Ratio and Concrete Strength on Beam Mid-Span Deflection

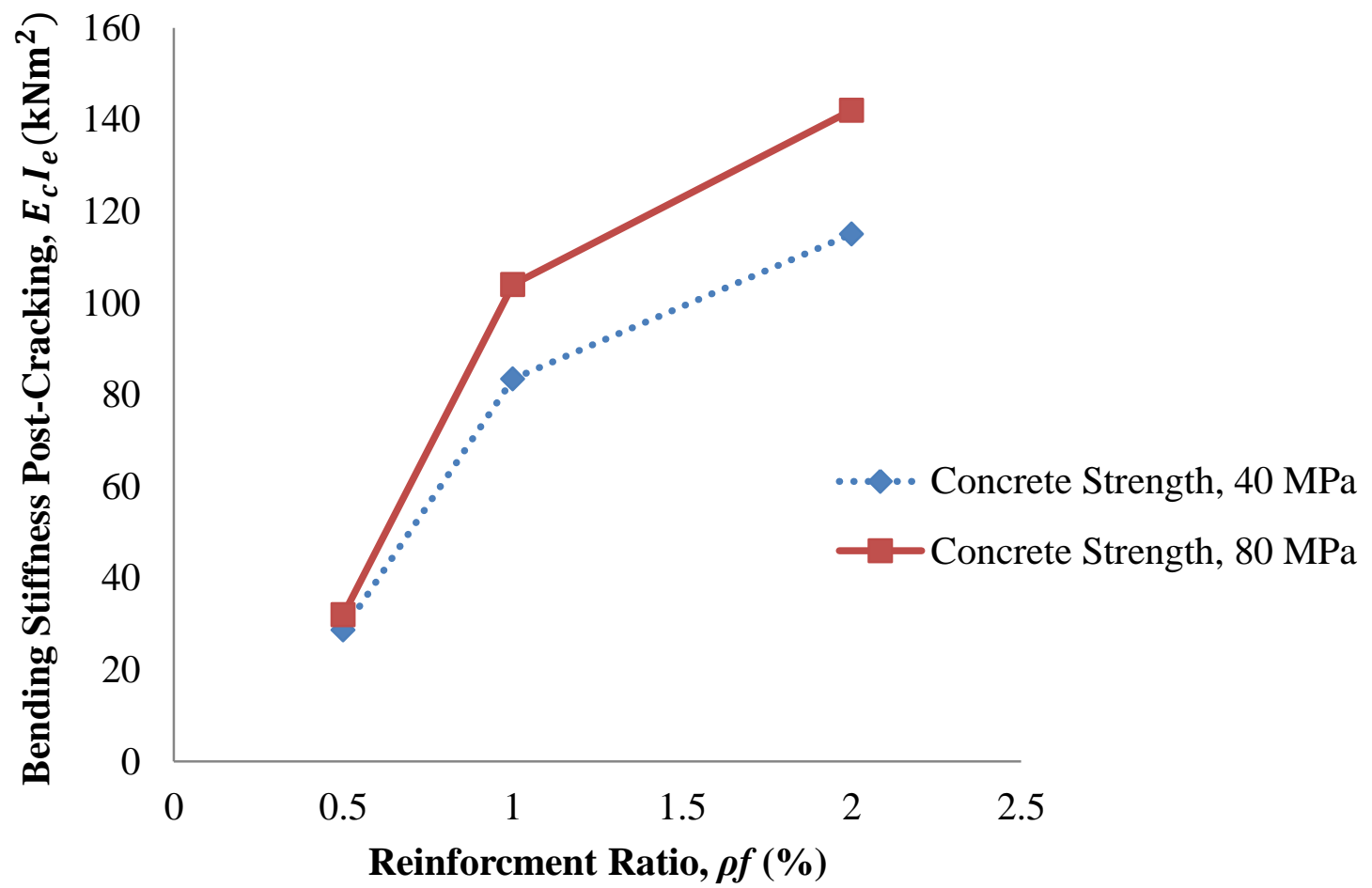

Fig. 12. Effect of Reinforcement Ratio and Concrete Strength on Bending Stiffness 


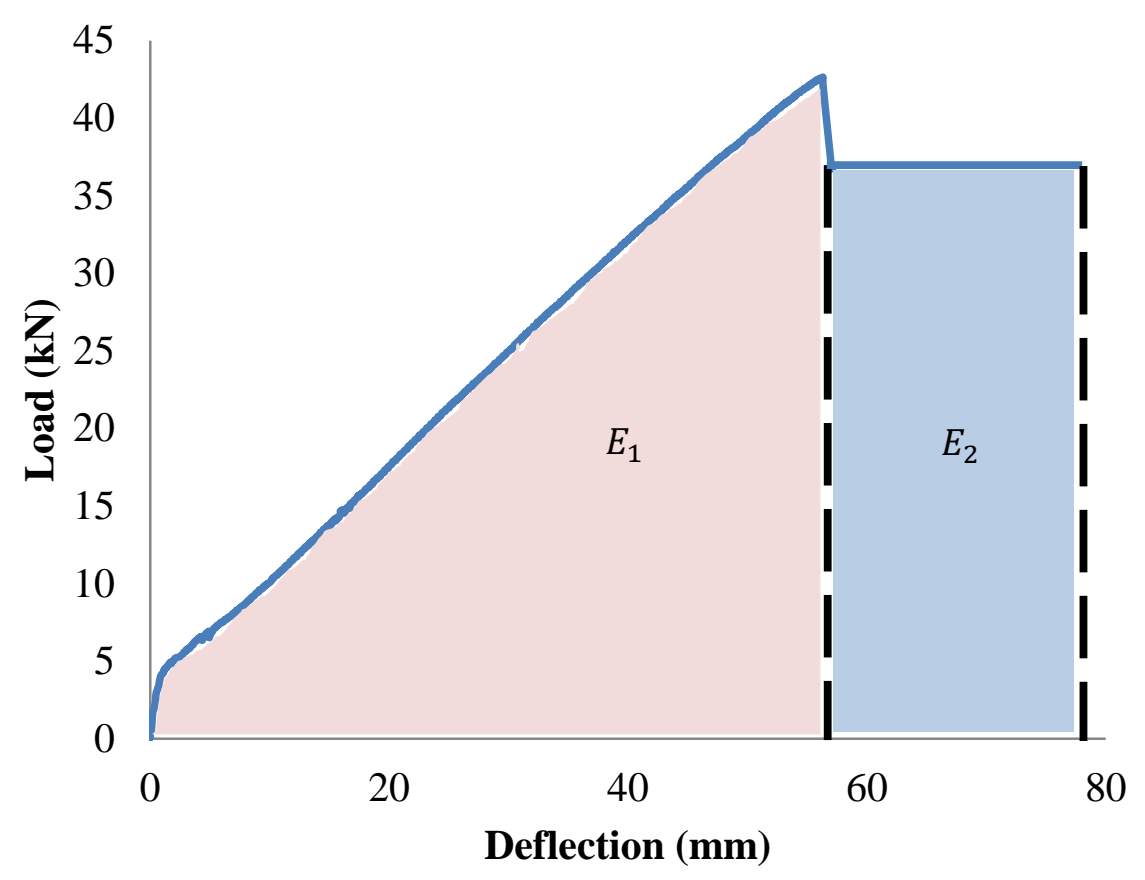

Fig 13. Energy Absorption Capacity $\left(E_{1}\right.$ and $\left.E_{2}\right)$ Calculation

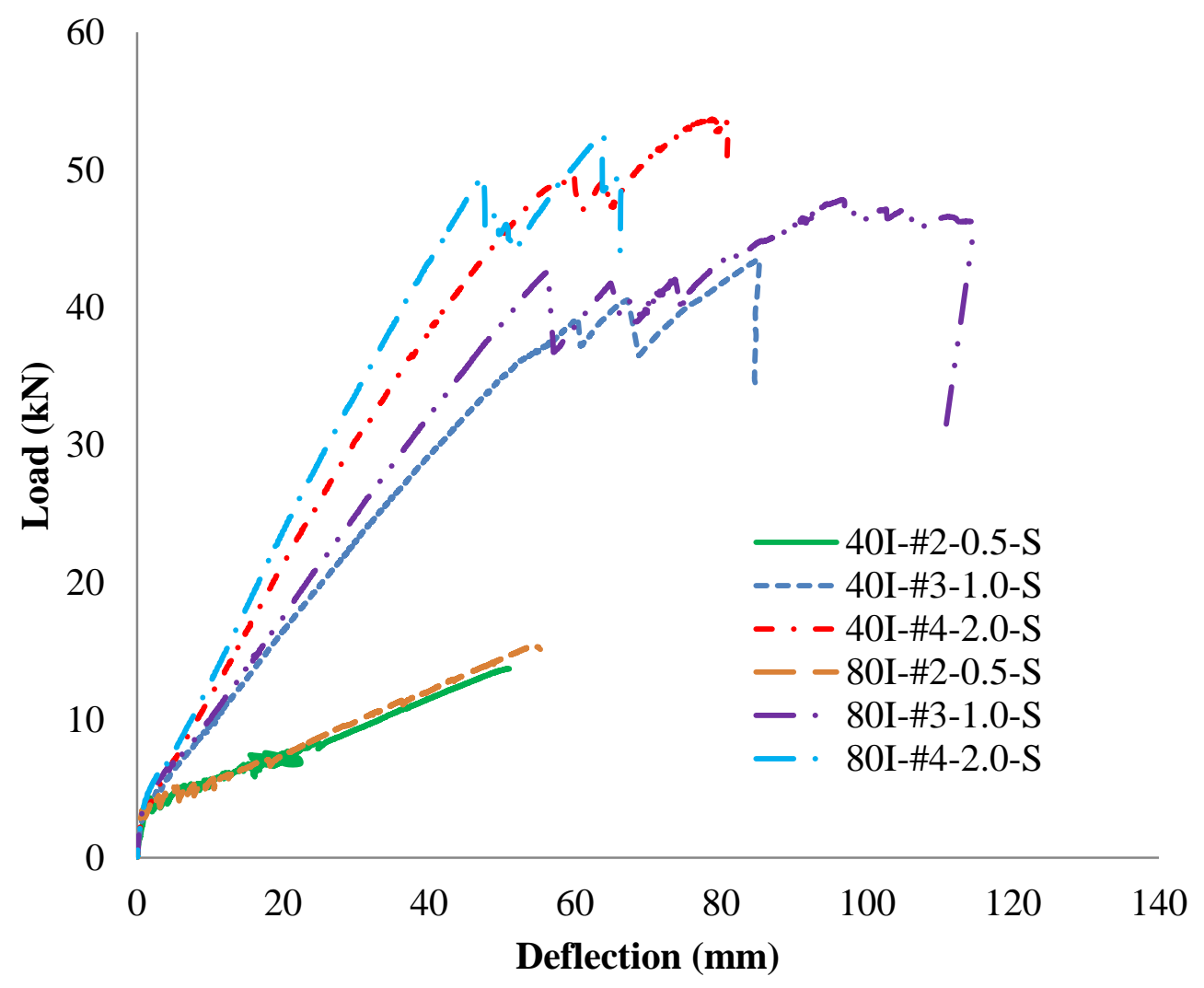

Fig. 14. Load-Deflection Relationship of GFRP RC Beams 


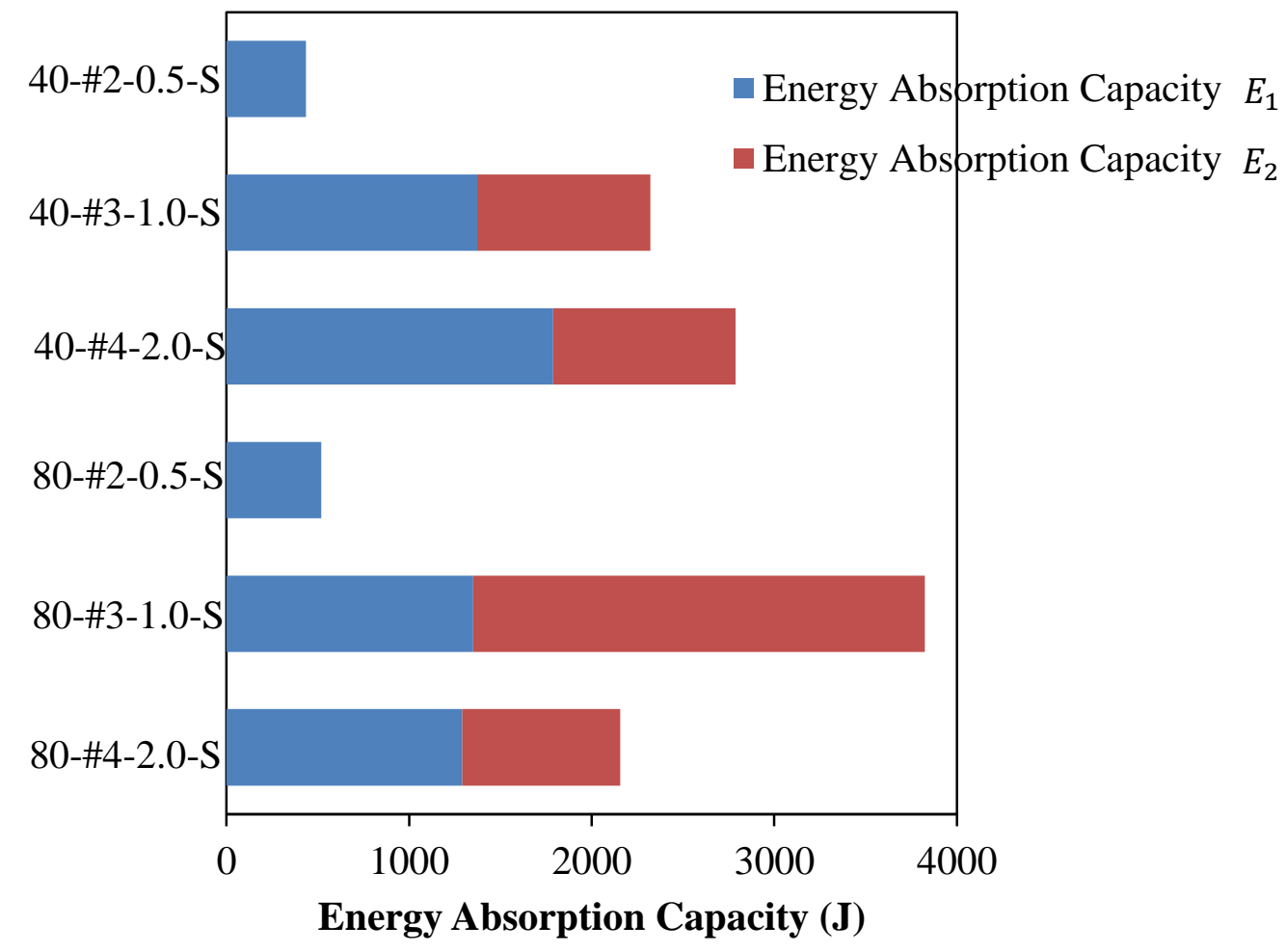

Fig. 15. Energy Absorption Capacity of GFRP RC Beams under Static Loading

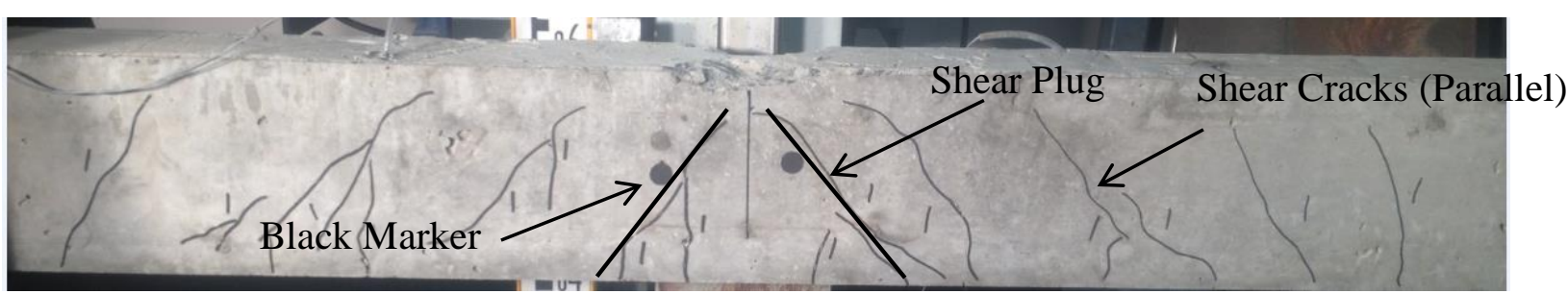

Fig. 16. Shear Plug of GFRP RC Beam 80-\#3-1.0-I under Impact Loading

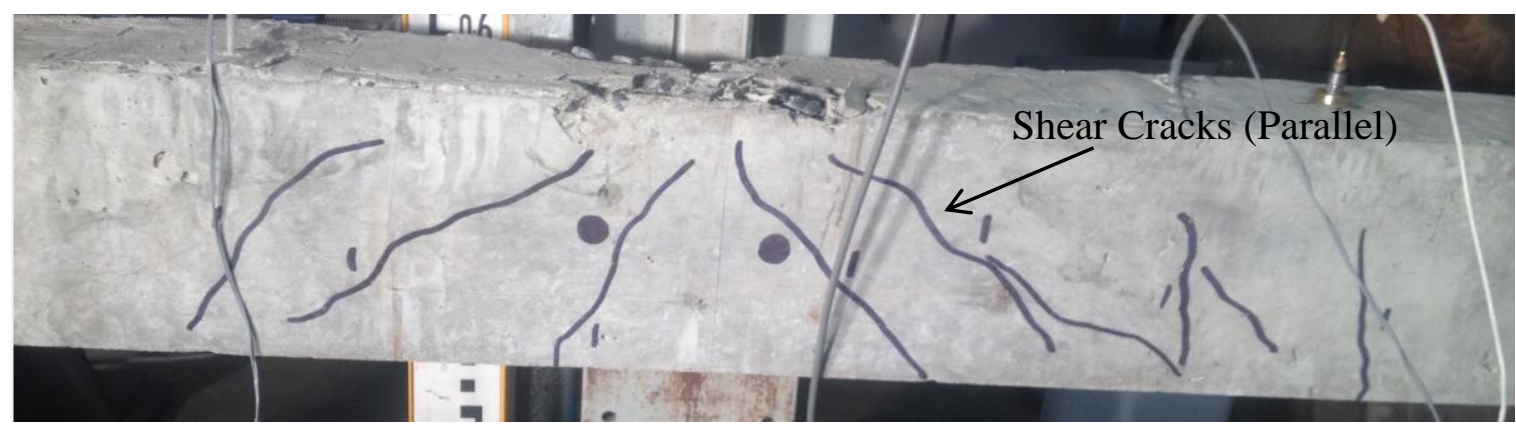

Fig. 17. Shear Plug of GFRP RC Beam 80-\#4-2.0-I under Impact Loading 


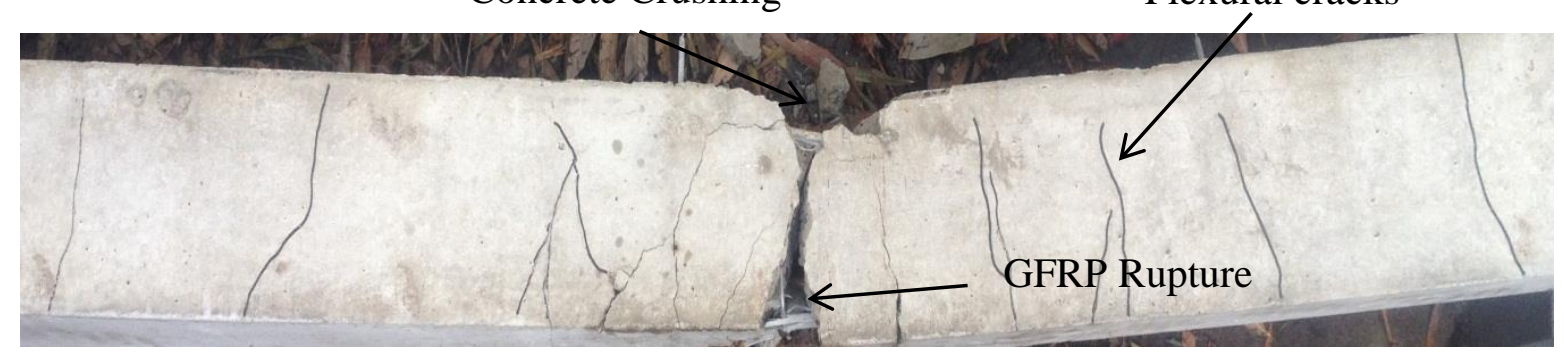

Fig. 18. Balanced Failure of GFRP RC Beam 40-\#2-0.5-I under Impact Loading

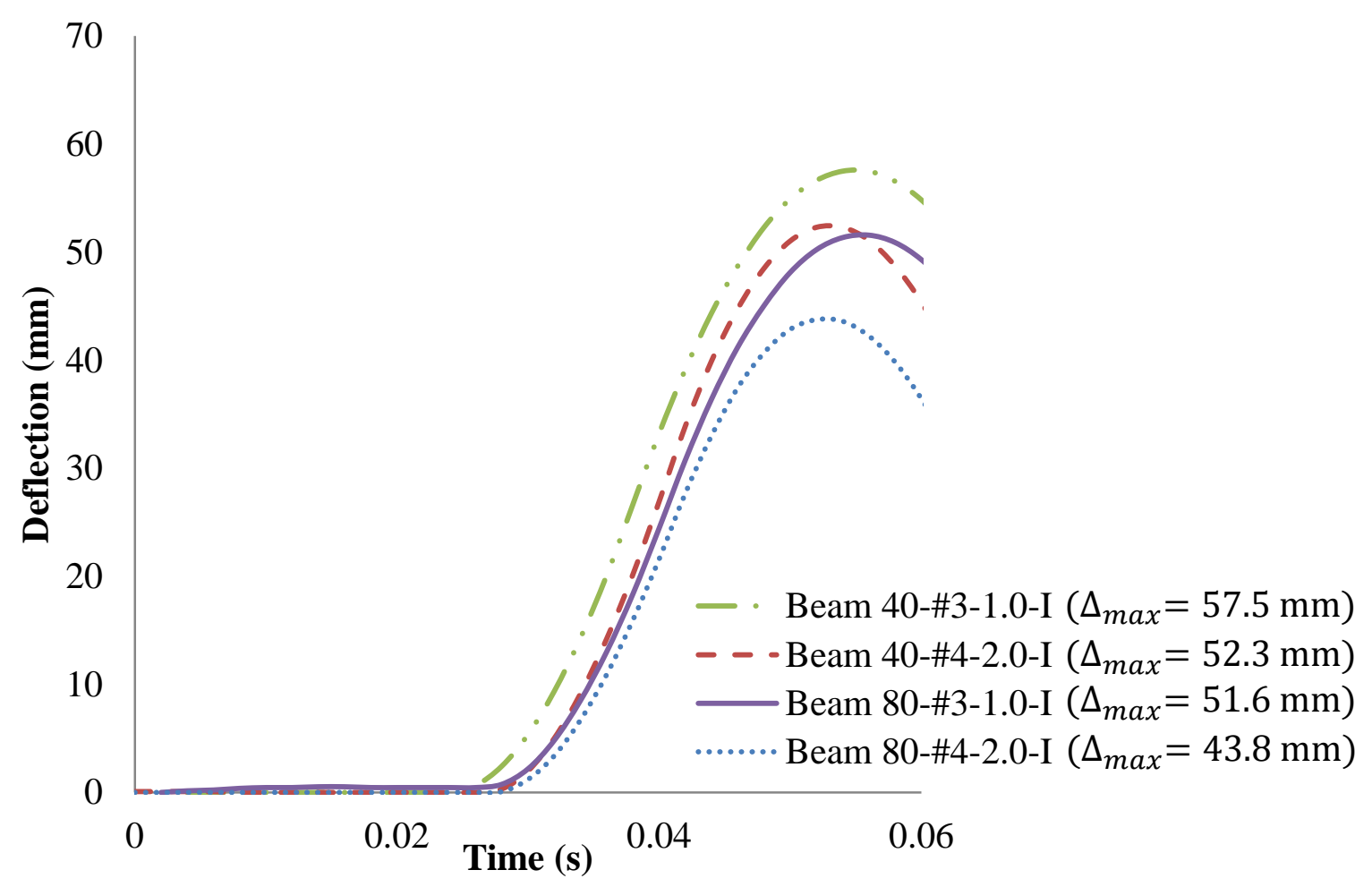

Fig. 19. Dynamic Mid-Span Deflections of GFRP RC Beams from Image Processing of High-Speed Video Recordings 


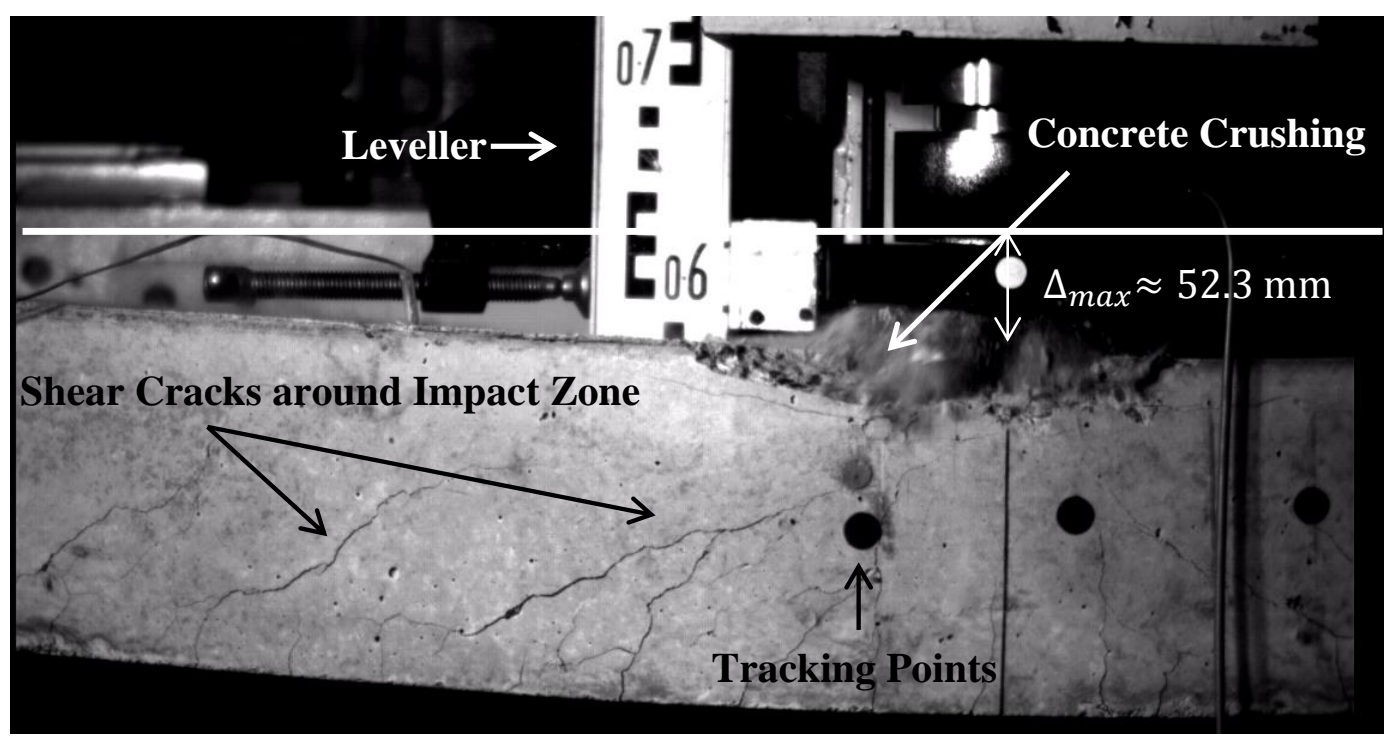

Fig. 20. High Speed Camera at Mid-Span Deflection of GFRP RC Beam 40-\#4-2.0-I under Impact Loading

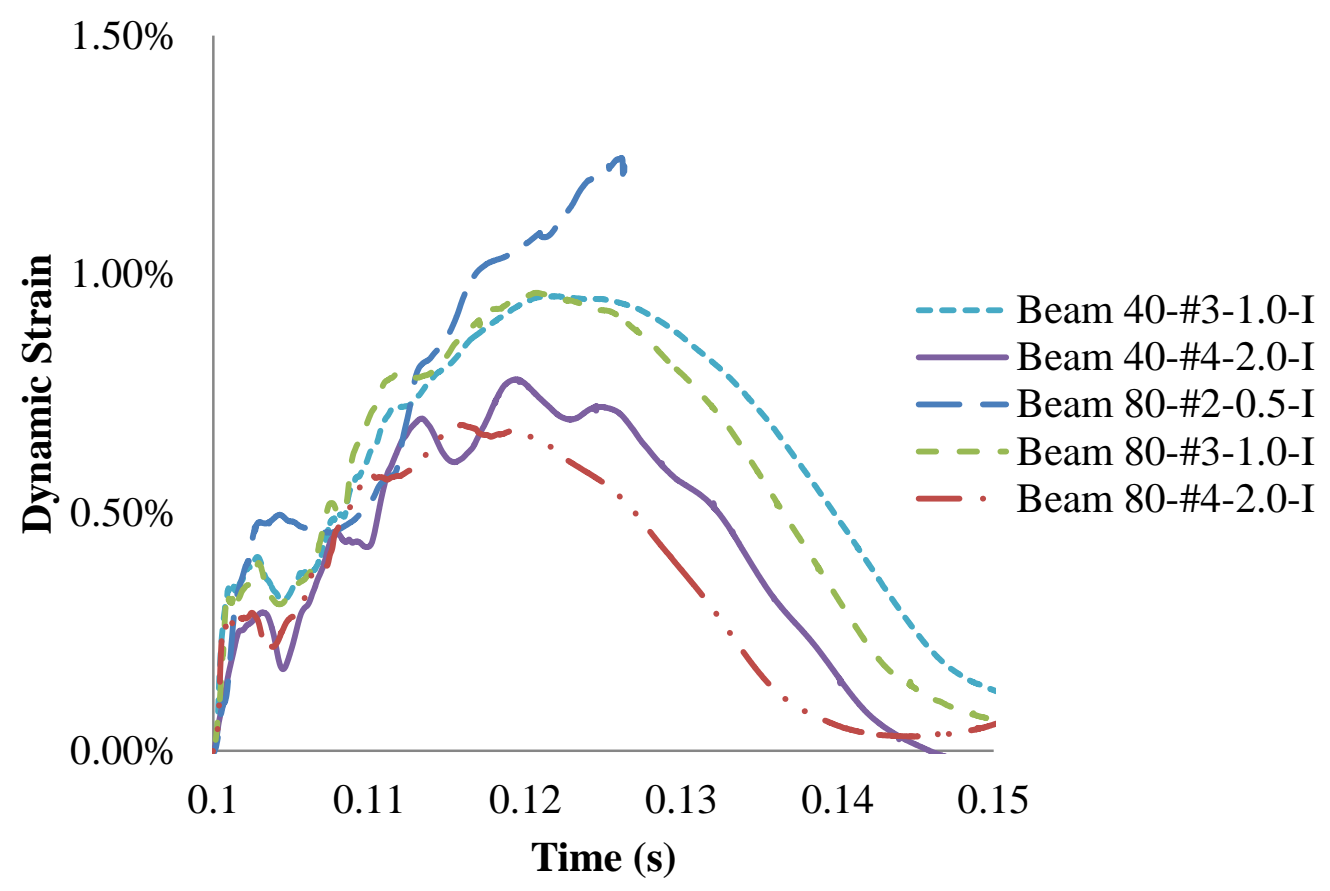

Fig. 21. Dynamic Strain Time History of GFRP RC beams 


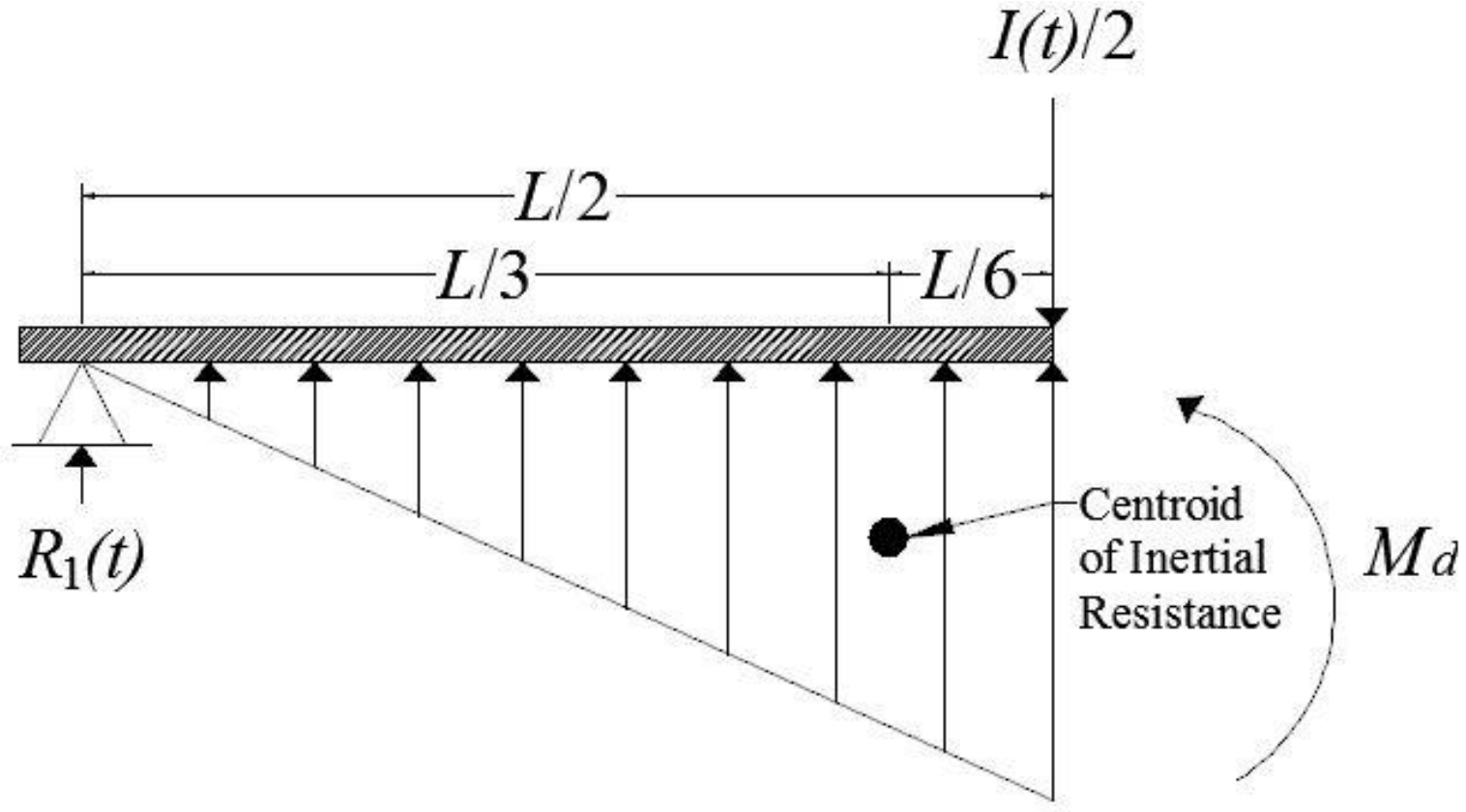

Fig. 22. Free Body Diagram for Dynamic Moment Capacity Calculation

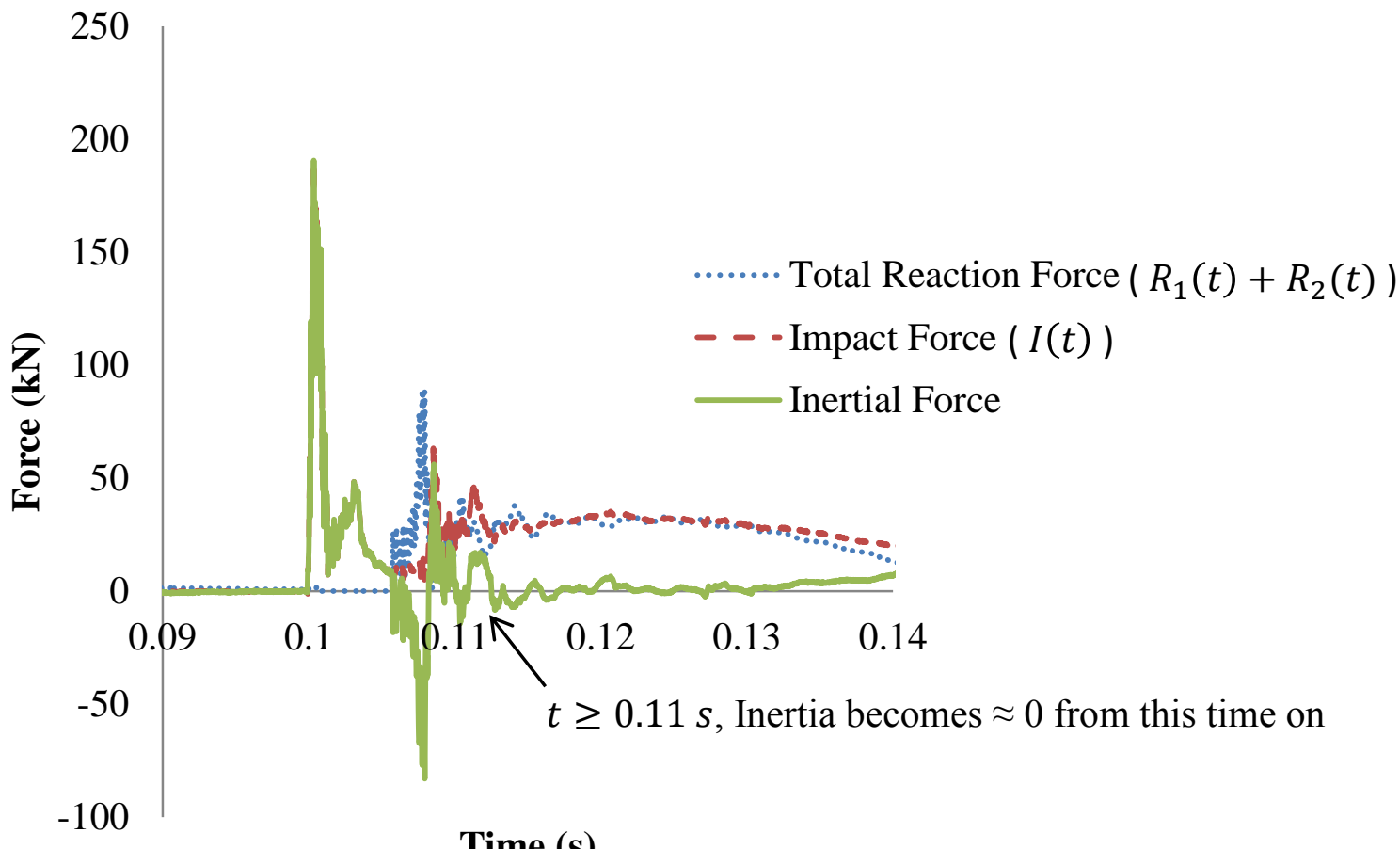

Fig. 23. Breakdown of Resisting Forces for GFRP RC Beam 40-\#3-1.0-I under Impact Loading 


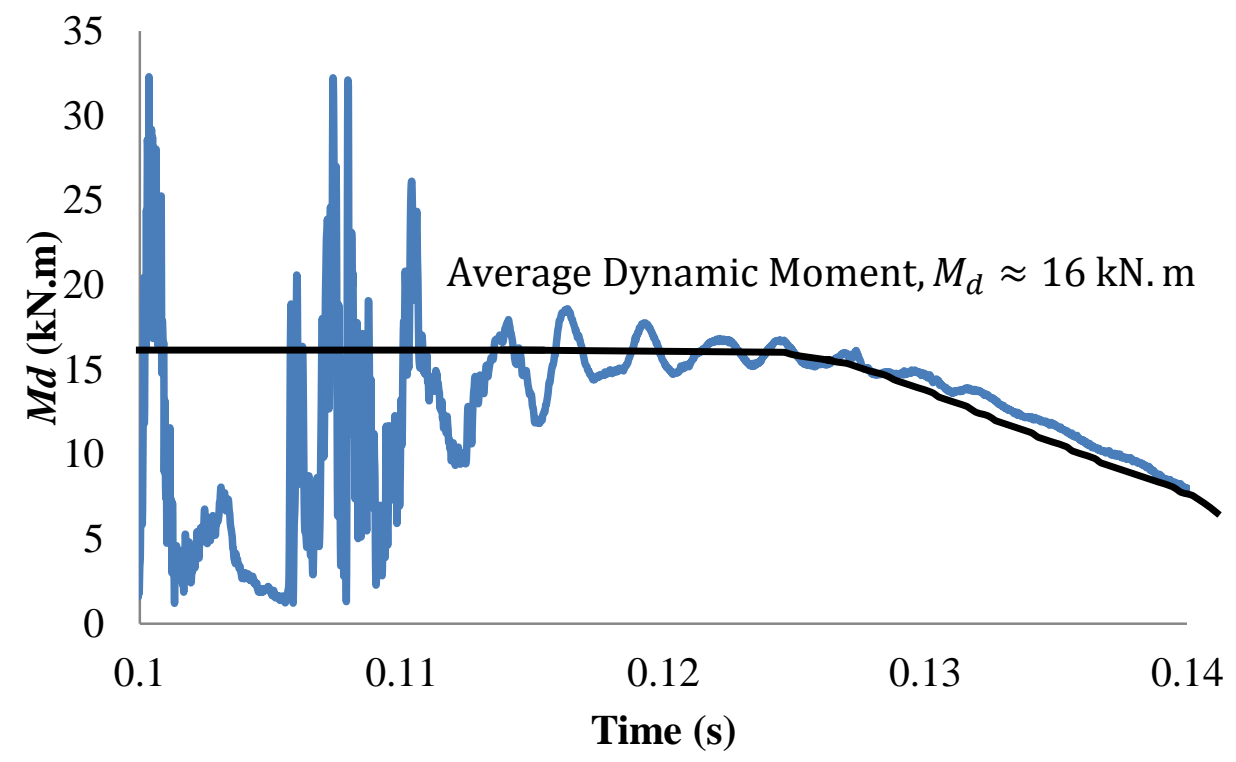

Fig. 24. Average Dynamic Moment for GFRP RC Beam 40-\#3-1.0-I under Impact Loading

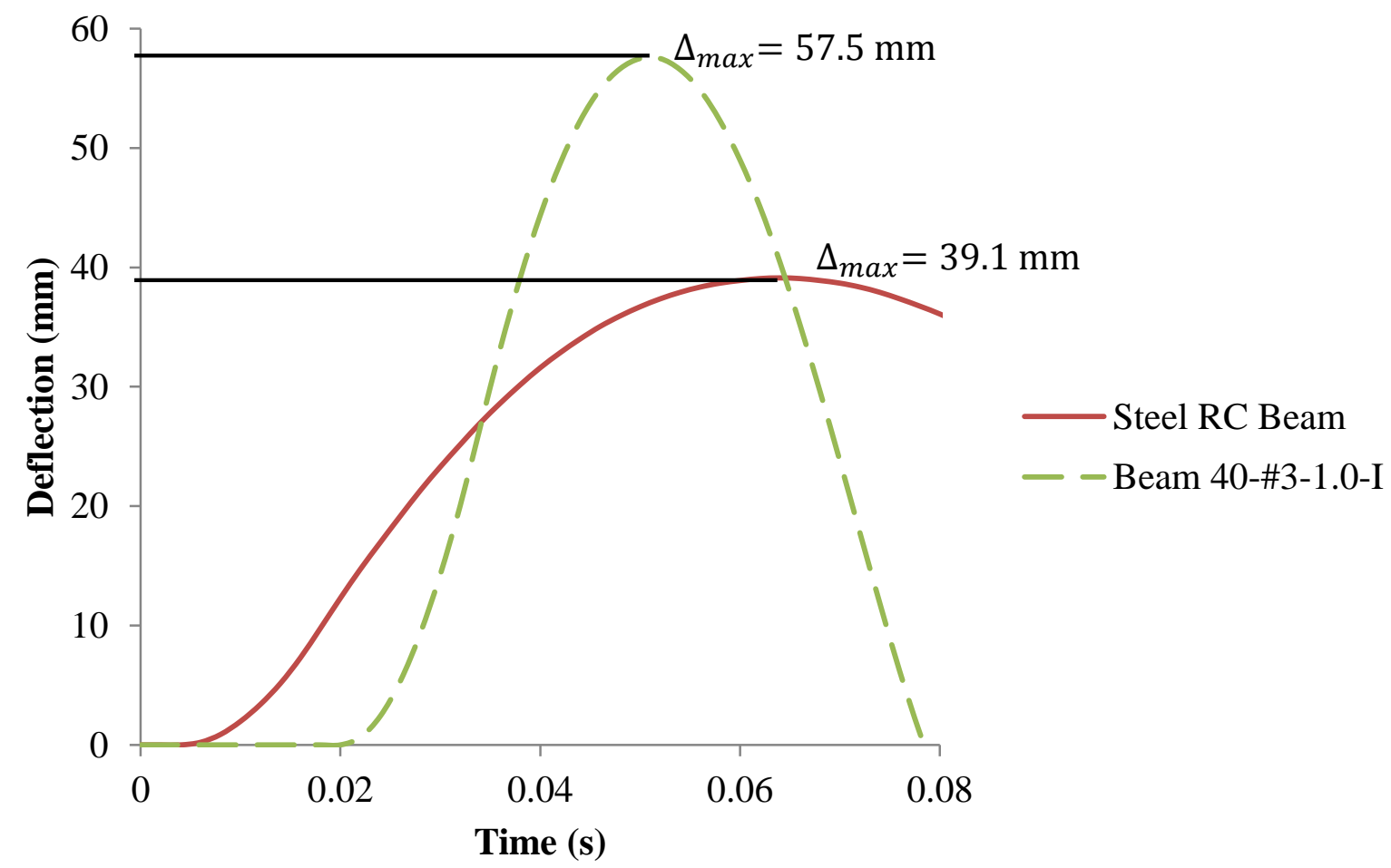

Fig. 25. Comparative Analysis of Mid-Span Deflection 


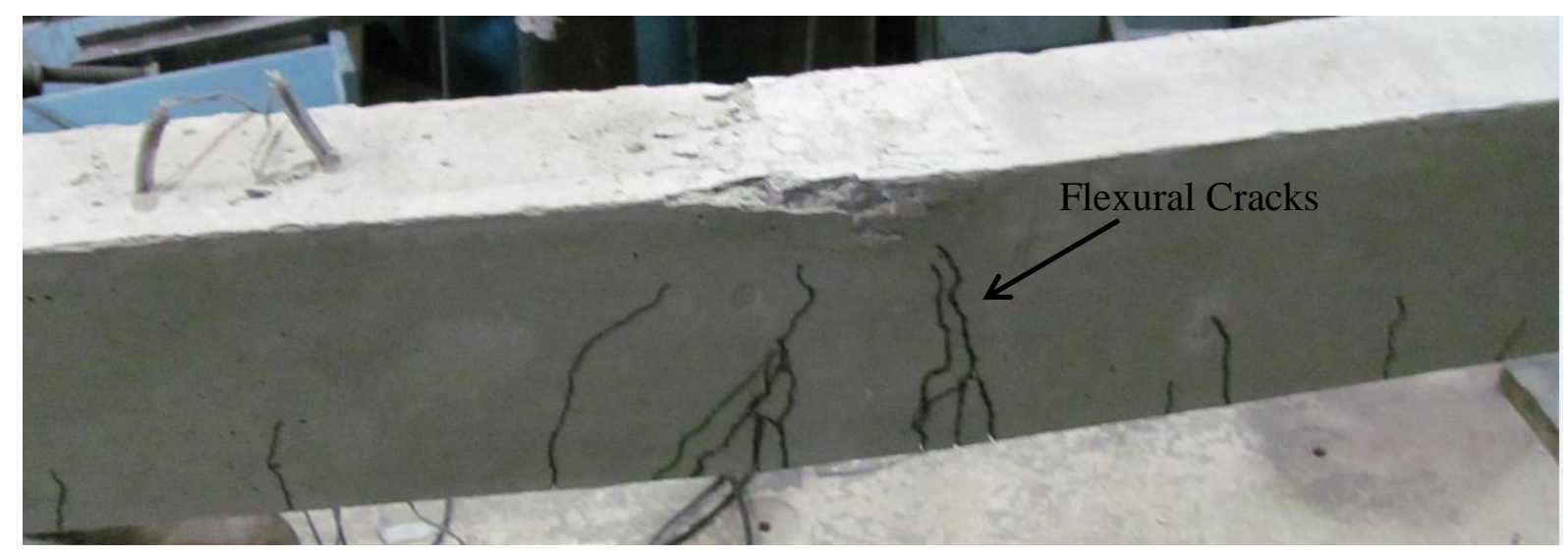

Fig. 26. Steel RC Beam after Impact Loading

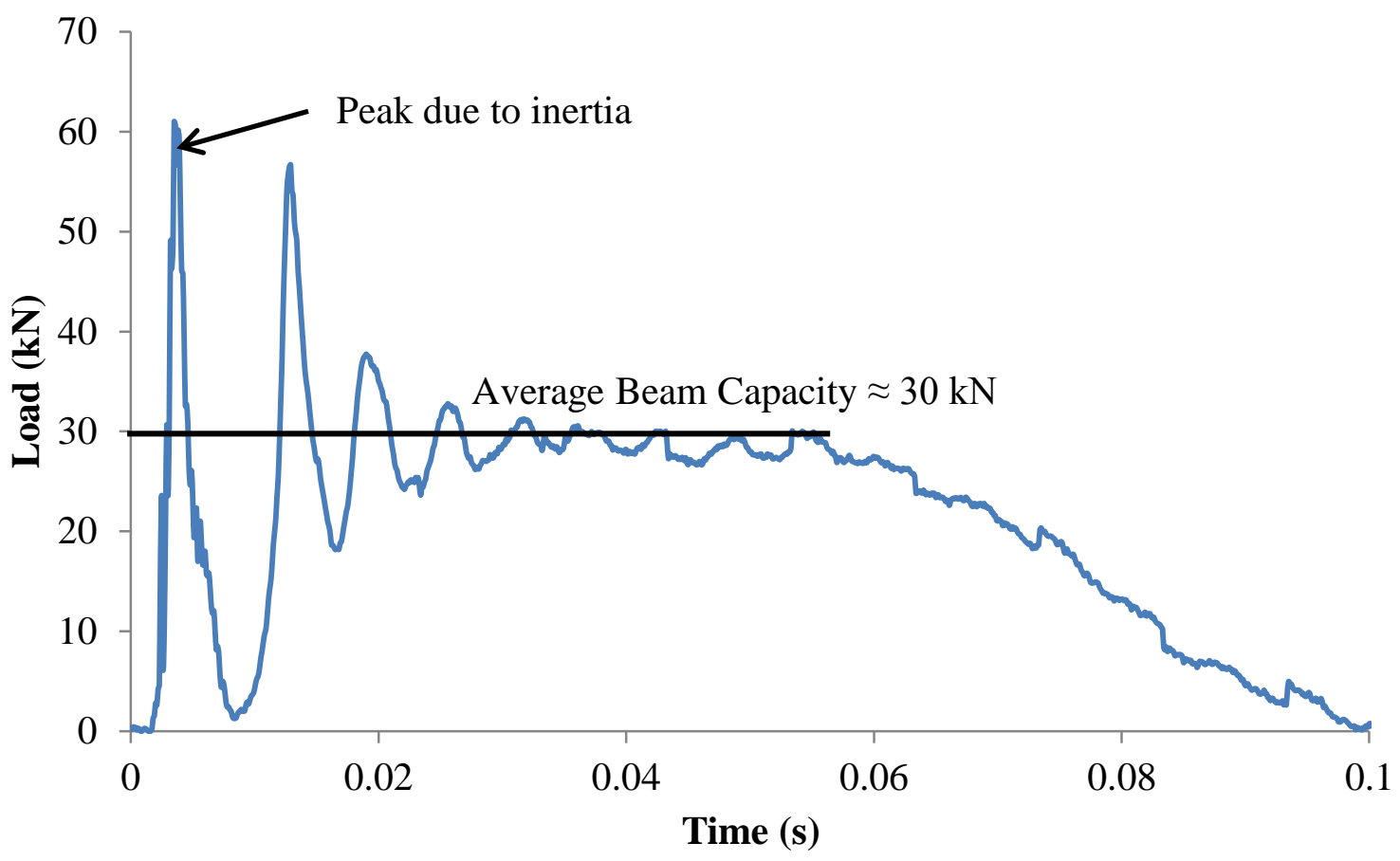

Fig. 27. Load-Time History of Steel RC Beam 


\section{NOMENCLATURE}

$A_{f} \quad$ area of FRP tensile reinforcement

$a$

acceleration of the GFRP RC beam under impact loading

$d \quad$ distance from extreme compression fibre to centroid of longitudinal tensile reinforcement

$E_{a b s} \quad$ energy absorption of GFRP RC beam

$E_{c}$

elastic modulus of concrete

$E_{f}$

elastic modulus of GFRP reinforcement

$f_{u}$

tensile strength of GFRP reinforcement

$g$

acceleration due to gravity

$h \quad$ height of drop hammer

$I_{e} \quad$ effective moment of inertia

$I(t) \quad$ impact force as a function of time

$L$

length of GFRP RC beam or free length of the tensile test specimen

$L_{a}$

$L_{\text {tot }}$

$M_{d}$

$M_{n}$

$M_{u}$

$m$

length of steel anchors used for tensile test specimens

total length of tensile test specimen

experimental dynamic moment capacity of GFRP RC beam

design nominal moment capacity of GFRP RC beam

experimental moment capacity of GFRP RC beam

mass of drop hammer

$\bar{m}$

mass per unit length of GFRP RC beam

$P_{c r}$

$P_{u}$

$R_{1}(t)$

$R_{2}(t)$

$t$

$v$

$x$

experimental cracking load

experimental load carrying capacity

support reaction 1 force as a function of time

support reaction 2 force as a function of time

time

velocity of drop hammer

distance from support along the length of the GFRP RC beam

$\Delta_{\max }$

experimental mid-span deflection

$\varepsilon_{\text {c.avg }}$

$\varepsilon_{c u}$

average strain in concrete from two strain gauges

assumed ultimate strain in concrete, taken as 0.003

$\varepsilon_{f r p}$

strain in one GFRP tensile reinforcement strain gauge

$\varepsilon_{\text {frp.avg }}$

$\varepsilon_{f u}$

average strain of two GFRP strain gauges on tensile reinforcement

$\rho_{f}$

rupture strain of GFRP tensile reinforcement

$\rho_{f b}$

GFRP longitudinal reinforcement ratio

balanced GFRP longitudinal reinforcement ratio

$\emptyset$

diameter of GFRP reinforcement bar 